


\title{
Production of high-quality extremely-thin histological sections by ultrasonically assisted cutting
}

\author{
Dong Wang ${ }^{\text {a, }}{ }^{*}$, Anish Roy ${ }^{a}$, Vadim V. Silberschmidt ${ }^{\text {a }}$
}

a Woflson School of Mechanical, Electrical and Manufacturing Engineering, Loughborough University, Loughborough, LE11 3TU, UK

b Biomechanics Group, Department of Mechanical Engineering, Imperial College London, London, SW7 2AZ, UK

*Corresponding author. Tel: 00447500564659

Email address: d.wang@lboro.ac.uk;

\begin{abstract}
Modern-day histology of biological tissues requires precision cutting of a wide variety of tissue samples for histological analyses. Lots of common problems can be identified at the conventional microtome sectioning including creation of curling sections and sections stick to the blade, which made high-quality sections hard to obtain. This paper deals with the development of next generation of microtomes employing introduction of a controlled ultrasonic vibration to process biological tissues. Based on a combination of advanced experimental and numerical studies of a novel cutting system with multi-body dynamics, this study investigated effects of cutting parameters and characteristics of ultrasonic excitation with the aim to design and manufacture an ultrasonically assisted cutting device (UACD) for microtomy. The cutting mechanism was detailed to show the advantages of the ultrasonically assisted cutting in the creation of high quality, thin sections. The novel prototype was designed and developed to conduct conventional cutting (CC) and ultrasonically assisted cutting (UAC) of biological tissues embedded in wax. Cutting forces, blade wear, blade damage and section quality for these cutting processes were assessed. It was found that the efficiency and quality of cutting were dependent on the level of cutting forces, which were lower in UAC compared with CC. The quality of cut samples with a thickness of $4 \mu \mathrm{m}$ was better in UAC than CC. The developed ultrasonically assisted cutting device also enables successfully sectioning of the thin biological samples with high precision, reduced blade wear and less blade damage. This will increase the blade life making both environmental and economic impacts.
\end{abstract}

Keywords: Ultrasonically assisted cutting; Precision cutting; Ultrasonically assisted cutting tool (device) design; Chip (section) formation and quality; Tool (blade) wear and damage; Microtome 


\section{Abbreviations}

CC ........ Conventional cutting

FEA......... Finite-element analysis

PTFE....... Polytetrafluoroethylene

UAC....... Ultrasonically assisted cutting

UACD...... Ultrasonically assisted cutting device

\section{Symbols}

$\begin{array}{ll}A & \text { Vibration amplitude } \\ b & \text { Sample width } \\ d_{*} & \text { Component diameter } \\ d_{31}, d_{33}, d_{15} & \text { Charge constants } \\ f & \text { Vibrating frequency } \\ F_{c} & \text { Sectioning (cutting) force } \\ F_{t} & \text { Transverse (orthogonal) force } \\ G_{c} & \text { Fracture toughness } \\ h & \text { Cut depth } \\ l_{*} & \text { Component length } \\ S_{33}^{E}, S_{11}^{E} & \text { Elastic compliances } \\ S_{Z} & \text { Area roughness (maximum height) } \\ t_{*} & \text { Component thickness } \\ U_{d} & \text { Minimum vibration amplitude } \\ U_{D} & \text { Maximum vibration amplitude } \\ U_{d} / U_{D} & \text { Vibration amplitude uniformity } \\ v & \text { Cutting speed } \\ V & \text { Voltage across the piezoelectric rings } \\ \text { x-direction } & \text { Orthogonal direction } \\ \text { z-direction } & \text { Cutting direction } \\ Z & \text { Electrical impedance } \\ \alpha & \text { Blade holder's tip angle } \\ \beta & \text { Blade holder's slot angle } \\ \gamma & \text { Blade angle } \\ \varepsilon_{33}^{T} \cdot \varepsilon_{33}^{-1} & \text { Dielectric constants } \\ \theta & \text { Clearance angle } \\ \sigma & \text { Density } \\ \sigma_{Y} & \text { Poisson's ratio } \\ & \end{array}$




\section{Introduction}

The microtome has become a universal tool for creation of thin slices of biological tissue samples for microscopic inspection in histology. For optimal detection of tissue abnormalities under a microscope, microtome cutting must be defect free with uniform section thickness as it affects the contrast, sharpness within the microscopic image of the slide. Typically, a microtome has a blade mounted in a blade holder, and a tissue sample embedded in a wax block is moved relative to the blade along a pre-defined path thereby cutting a thin section from the block. The section is then floated in a water bath, placed on a slide and stained for light microscopy. These tissue sections range from a thickness of $50 \mathrm{~nm}$ to $100 \mu \mathrm{m}$ depending on the type of biological tissue under study. Usually, they are cut at a thickness of 3-5 $\mu$ m ensuring that only a single layer of cells makes up the section.

The current design of microtomes has largely remained unchanged from the introduction of the first microtome in the $19^{\text {th }}$ century by Wilhelm His (Hopwood, 2000). The earliest form of the microtome enabled free hand sectioning by using a sharp razor. Modern microtomes are precision instruments incorporating micro-controllers to cut uniformly thin sections. Central to the production of good sections is the microtome blade. Bancroft and Gamble, (2008) thought disposable blades have revolutionised microtomy by improving the precision of cuts and producing flawless thin sections. However, disposable blades are often unsatisfactory for sectioning harder tissues, especially bone. Attempts are made by Mohammed et al., (2012) to produce adequate cutting surfaces through sharping the blade edge, use of cutting resistant materials, optimisation of blade edge profiles and coating on the blade edge.

Recently, some design features are introduced in the microtome to improve the relative ease of changing cutting blades, however, this process is still a costly and time-consuming operation. This is mainly due to the time required to 'cut in' a new blade as well as the cost of the new blade itself. Moreover, Kapelsohn, (2015) found lots of common problems could be identified at the use of the microtome blade including squishing of the edges of the tissue due to a blunt microtome blade and longitudinal tears in the tissue due to nicks in the microtome blade. It is therefore important to prolong the blade life and improve the cutting process in microtomy for increased efficiency in histology. Research data on the life of microtome blades is not available in the published literature. However, the global microtome market size was estimated at \$48.6 million in 2016 and expected to reach $\$ 73.5$ million by 2025. Microtome blades are anticipated to witness fastest growth over the years as well (Grand View Research, 2017). Therefore, it is widely accepted that even a small increase in blade life would allow for lower cost in histology, yielding substantial savings in healthcare.

\section{Conventional cutting (CC) and ultrasonically assisted cutting (UAC)}

\subsection{Factors related to microtome cutting}

Mechanics of tissue cutting is a complex process which depends on several factors. Quintessentially, the sample quality is known to depend on the cutting forces imposed on the sample block during sample preparation. Factors which influence cutting forces are blade sharpness, the angle of the blade tip with the workpiece, cutting speed 
and temperature. A sharp blade edge free from imperfection helps to produce good sections as it reduces the net cutting forces during the process. Reilly et al., (2004) found the radius of the cutting edge influences the cutting forces. Setting a correct blade angle during microtomy is known by (Allison and Vincent, 1990) to reduce unwanted compressive stresses and improving blade longevity. In conventional cutting (for cutting speeds ranging from low to medium) an increase in cutting speed typically increase the cutting forces and affect the surface finish detrimentally, which were found by WILLIS and VINCENT, (1995). This is mainly due to an increase in imposed strain-rate in the workpiece material, which is referred to as the strain-rate hardening effect. The final key factor that affects surface quality is temperature. This includes the temperature of the sample being cut accounting for the temperature increase due to the cutting process (friction effect and plastic work). The effect of heat is reduced by decreasing the temperature of the sample block, this can be achieved with the use of cold plates, which has become the standard practice in microtomy.

\subsection{Mechanism of section formation}

Williams and Patel (2016) mentioned the behaviour of the section (chip) is governed by its thickness in the cutting process. When the cutting depth is small in value, the mechanism of section formation by a process of shear is named as shear cutting mode, where continuous, smooth sections without curling can be obtained. The mechanism of the thin section formation were found by Liao and Axinte, (2016) and Merchant (1945). Microtome sectioning forces provide the external work, which is dissipated as fracture toughness, friction and plastic work via shear. It can be explained using the Eq.1 from (Williams and Patel, 2016).

$$
\frac{F_{c}}{b}+\frac{F_{t}}{b} \tan \phi=G_{c}+\frac{\sigma_{Y} h}{2} \tan \phi+\frac{1}{\tan \phi}
$$

where $F_{c}$ is sectioning (cutting) force, $F_{t}$ is transverse (orthogonal) force, $b$ is the sample width, $\phi$ is shear plane angle, $G_{c}$ is energy per unit area at fracture (fracture toughness), $\sigma_{Y}$ is tensile yield stress, $h$ is cut depth.

According to the fracture mechanics, the fracture failure occurs when the energy release rate exceeds the critical value (fracture toughness) at the certain loading mode. In the microtome sectioning, the energy released rate is proportional to the cutting forces because it is mainly supplied by the external work. This means with the increase of the cutting forces, the value of energy release rate increases, which make fracture occurs easily and continuous sections difficult to obtain.

Therefore, there is a significant demand to improve the cutting process and the quality of section by reducing cutting forces along both parallel and perpendicular to cutting directions.

\subsection{Ultrasonically assisted cutting forces}

Interestingly, studies of ultrasonically assisted machining of hard-to-cut metal alloys from Nath and Rahman, (2008) for turning and Zhou et al., (2006) for diamond cutting show significant improvements in machining quality via a noticeable reduction in cutting forces with a reduced tool wear, thanks to a considerable reduction of friction and contact time between a tool and a workpiece. Ultrasonically assisted cutting experiments have been successfully performed on woods with cutting forces reduction and continuous chips in thickness of $200 \mu \mathrm{m}$ by Sinn et al., (2005). Studies from Ma et al., (2004) and Zhang et al., (2016) also show that continuous and straighten 
chips can be obtained and pulled out away from the workpiece easier than conventional cutting when vibration motion of the cutting tool applied perpendicular to the cutting direction. Therefore, applying ultrasonic vibration along both parallel and perpendicular to cutting direction could improve the cutting process by promoting section/ribbon generation and removal and extend the blade life by reducing cutting forces. To achieve this, an ultrasonically assisted cutting device (UACD) could be developed, which applied UAC with an inclination with respect to the sectioning direction. Similar with the ultrasonic elliptical vibration cutting conducted by Ma et al., (2004), the inclined UACD is generally controlled to vibrate along the cutting direction and the section (chip) flow direction. Intermittent cutting happened both at the cutting direction and chip flow direction, which reduces the friction and forces at the both directions.

Due to an ultrasonically assisted cutting device incorporated in a microtome is a novel concept in histology, for viable use in the future, it is important to analyse and understand the effect of this cutting system thoroughly.

\subsection{Mechanism of inclined ultrasonically assisted cutting}

In this process, the blade is vibrated at a frequency of $f$ and an amplitude of $A$ with a clearance angle of $\theta$. The trajectory of the blade to the sample block can be expressed

$$
\begin{gathered}
z(t)=A \sin \theta \cdot \cos 2 \pi f t+v t \\
x(t)=A \cos \theta \cdot \cos 2 \pi f t
\end{gathered}
$$

where $z$ and $x$ directions are parallel and perpendicular to the cutting direction respectively and $v$ is the speed of the block moving. Fig. 1 provides a schematic illustration of the trajectory.

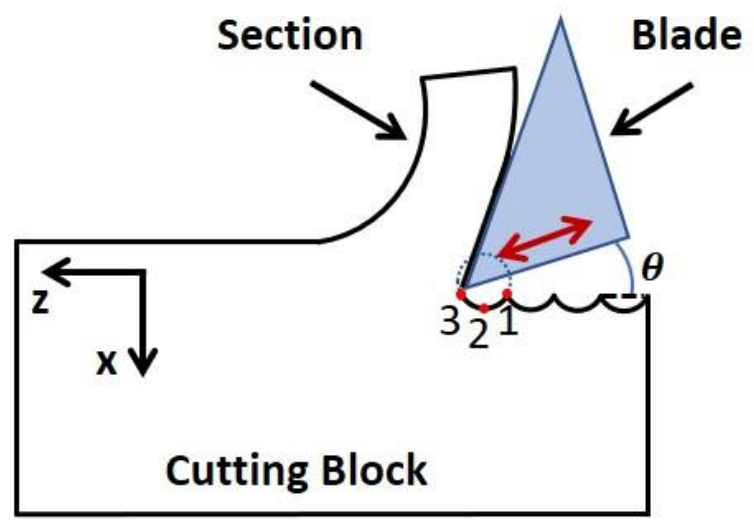

Fig. 1 Mechanism of ultrasonically assisted cutting with inclination to cutting block

The relative motion speed of blade to the block is 


$$
\begin{gathered}
v_{z}=-2 \pi f A \sin \theta \sin 2 \pi f t+v \\
v_{x}=-2 \pi f A \cos \theta \sin 2 \pi f t
\end{gathered}
$$

The cutting can be divided into separating type and non-separating type. When $v_{z}>0$, the blade is separated from the section and the block in each cycle of the vibration called the separating type UAC. When $v_{z}<0$, the blade is contacting with the section and the block in each vibration cycle called non-separating type UAC. It is clear that the cutting forces in UAC should be lower than the cutting forces in conventional continuous cutting due to the existing of separating type cutting in UAC.

As illustrated in Fig. 1, the blade starts to cut the block at the point of 1 in each cycle of the vibration and a section is being generated. Then, the blade is reaching to the lowest vibration point 2 , where the horizontal and vertical vibration speeds are zero. From the point 2 to 3 , there are contact between the section and the blade due to $v_{z}<0$. But the rake face of the blade starts to move upward in the vertical direction. The friction direction between the blade rake face and the section is reversed as compared with it in CC. The reverse of the friction could assist in pulling out the section away from the block. Due to the rake face of the blade pulls the chip upward, a more straighten, less curled section could be formed. The blade separates from the section at point 3 , when $v_{z}>0$ at the blade retraction.

Thus, the inclined ultrasonically assisted cutting reduces cutting forces at both parallel and perpendicular to cutting direction, forms smooth sections and promotes the section removal.

\section{Methodology}

To conduct UAC of biological samples, an ultrasonically assisted cutting device was designed, manufactured and characterised. The device was fixed on an existing microtome (HM355s Automatic Microtome, Thermo Fisher Scientific Inc.) with an easy clamping feature, allowing users to continue using their original microtomes with the addition of an UAC tool attachment. A test rig was also developed for measuring cutting forces during the process of CC and UAC. Due to the mentioned factors affecting the cutting forces, within this study the effect of speed and temperature have been taken into account by maintain a constant room temperature and a constant cutting speed. Additionally, an optimum blade angle was set by an experienced histologist for all experimental studies. Measurements of blade wear were conducted before and after $\mathrm{CC}$ and UAC as well to differentiate the blade damage.

\subsection{Design of ultrasonically assisted cutting device}

Finite-element analysis (FEA) is widely used as a design and analysis tool for ultrasonic transducers thanks to its ability to accurately calculate vibration modes for complex geometries, including stress and strain distributions. The modal analysis of the FEA is a powerful tool to assess the vibrational characteristics. Additionally, FEA has been extensively used to simulation of piezoelectric mechanical interaction.

\subsubsection{Design}


The ultrasonically assisted cutting device was designed as a Langevin transducer to enable transmission of longitudinal vibrations, excited by a piezoelectric stack and translated onto the cutting blade, which was accommodated and held in a holder. The profile of the holder was inspired by prior studies for cutting bones [Cardoni et al., (2006)]. The device was divided into four sections: the cutting tip, the blade holder body, the tapered section and the base, as illustrated in Fig. 2. The cutting tip had a sharp edge with a pre designed slot, used for clamping the blade. The blade body had a constant thickness with its length being larger than the stroke length (36 mm) for the sample movement. The length and thickness of the blade body were optimised to ensure uniformity of vibrations along the cutting width. Two threaded holes were drilled on the sides at the node positions (labelled as the mounting spot in Fig. 2), allowing attaching or mounting of the holder on the microtome. A tapered section was located between the body and the base; this tapered section was used to amplify the vibration amplitude. An increased gain was achieved by applying a large rate of change in the cross-sectional area. A threaded hole was tapped at the base of the holder to attach the front mass to the transducer. The piezoceramic rings were sandwiched between the holder base and a back mass through a central bolt, which was tightened to provide a precise amount of compression preventing ring failure, reducing transducer losses and stabilizing the operating frequency. Electrodes were deposited on opposite faces of the piezoelectric rings for applying the excitation voltage.

Stainless steel grade 316, commonly used for biomedical devices, was used as the holder material. The disposable blades used in this work were made of stainless steels as well. The piezoceramic ring used was PZT401 from Morgan technical ceramics. This material is known for its high mechanical quality factor and ideal for high-power applications. The dimensions of the designed device were listed in the table 1. 


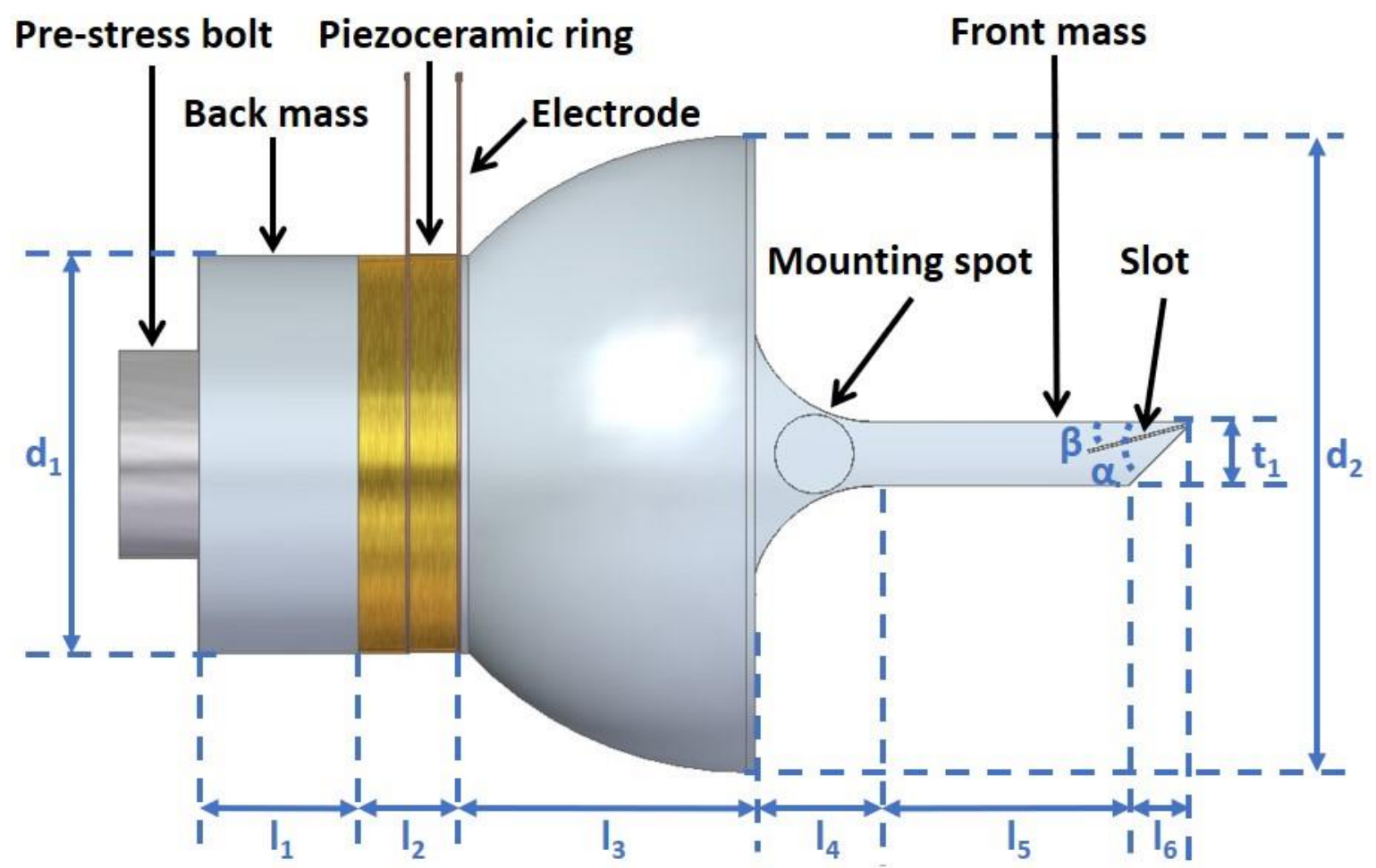

Fig. 2 Designed ultrasonically assisted cutting device (UACD)

Table 1 The dimensions of the UACD in units of $\mathrm{mm}$ and degree for angles

\begin{tabular}{|c|c|c|c|c|c|c|c|c|c|c|c|c|c|c|c|}
\hline \multirow{2}{*}{\multicolumn{2}{|c|}{$\begin{array}{l}\text { Back } \\
\text { mass }\end{array}$}} & \multirow{2}{*}{\multicolumn{2}{|c|}{$\begin{array}{c}\text { Piezo- } \\
\text { ring }\end{array}$}} & \multirow{2}{*}{\multicolumn{3}{|c|}{ Electrode }} & \multicolumn{9}{|c|}{ Front mass } \\
\hline & & & & & & & \multicolumn{3}{|c|}{ Holder base } & \multirow{2}{*}{$\frac{\text { Tapered }}{\mathrm{I}_{4}}$} & \multirow{2}{*}{$\frac{\text { Body }}{I_{5}}$} & \multicolumn{3}{|c|}{ Cutting tip } & \multirow{2}{*}{$\frac{\text { Slot }}{\beta}$} \\
\hline $\mathrm{I}_{1}$ & $\mathrm{~d}_{1}$ & $t_{p}$ & $d_{1}$ & $\mathrm{I}_{2}$ & $t_{e}$ & $d_{1}$ & $\mathrm{I}_{3}$ & $d_{1}$ & $d_{2}$ & & & $\mathrm{I}_{6}$ & $t_{1}$ & $\alpha$ & \\
\hline 20 & 50 & 6 & 50 & 13 & 0.5 & 50 & 40 & 50 & 80 & 15 & 32 & 8 & 8 & 45 & 15 \\
\hline \multicolumn{3}{|c|}{ Length } & \multicolumn{3}{|c|}{ Diameter } & \multicolumn{2}{|c|}{ Thickness } & \multicolumn{3}{|c|}{ Angle } & & & & & \\
\hline \multicolumn{3}{|c|}{$I_{*}$} & \multicolumn{2}{|c|}{$\mathbf{d}_{*}$} & & \multicolumn{2}{|c|}{$\mathbf{t}_{*}$} & \multicolumn{3}{|c|}{$\alpha, \beta$} & & & & & \\
\hline
\end{tabular}

\subsubsection{Finite-element model}

A finite-element (FE) model was developed in the design stage to assess the transducer's modal frequencies and mode shapes. The model was developed using a general-purpose FE software ABAQUS v6.14. Dimensions of each part of the transducer (especially, the holder) were based on the driving resonant frequency to maximize the vibration amplitudes at the cutting tip of the blade.

For vibration and dynamic analysis of the transducer, the material properties of piezoelectric materials require 
consideration of their mechanical, electromechanical and electrical aspects. The materials' parameters for the components of the transducer used in the FE model are listed in Tables 2 and 3.

Table 2 Materials properties used in FEM

\begin{tabular}{c|c|c|c|c|c}
\hline Parts & Materials & $\begin{array}{c}\text { Density } \\
\left(\mathbf{k g} / \mathbf{m}^{3}\right)\end{array}$ & $\begin{array}{c}\text { Young's } \\
\text { modulus } \\
(\mathrm{GPa})\end{array}$ & $\begin{array}{c}\text { Poisson's } \\
\text { ratio }\end{array}$ & $\begin{array}{c}\text { Electrical } \\
\text { conductivity } \\
(\mathbf{S} / \mathrm{m})\end{array}$ \\
\hline $\begin{array}{c}\text { Front \& back } \\
\text { masses }\end{array}$ & $\begin{array}{c}\text { Stainless } \\
\text { steel }\end{array}$ & 7900 & 193 & 0.25 & - \\
\hline Central bolt & Steel & 7850 & 200 & 0.33 & - \\
\hline Electrodes & Copper & 8960 & 120 & 0.34 & $5.96 \times 10^{7}$ \\
\hline
\end{tabular}

Table 3 Properties of piezoelectric ceramic rings (PZT401) used in FEM ("Piezoelectric ceramics," 2016)

\begin{tabular}{c|c|c|c|c}
\hline Properties & Specification & Unit & Symbol & Value \\
\hline \multirow{4}{*}{ Mechanical } & Density & $\mathrm{kg} / \mathrm{m}^{3}$ & $\rho$ & 7600 \\
\cline { 2 - 5 } & Poisson's ratio & - & $\sigma$ & 0.31 \\
\cline { 2 - 5 } & Compliances & \multirow{2}{*}{$\mathrm{m}^{2} / \mathrm{N}$} & $S_{33}^{E}$ & $15.6 \times 10^{-12}$ \\
\cline { 4 - 5 } & & & $S_{11}^{E}$ & $12.7 \times 10^{-12}$ \\
\hline Dielectric & Dielectric constant & - & $\varepsilon_{33}^{T} \cdot \varepsilon_{0}^{-1}$ & 1395 \\
\hline \multirow{2}{*}{ Piezoelectric } & \multirow{2}{*}{ Charge constants } & \multirow{2}{*}{$\mathrm{c} / \mathrm{N}$} & $d_{33}$ & $315 \times 10^{-12}$ \\
\cline { 4 - 5 } & & & $d_{15}$ & $-132 \times 10^{-12}$ \\
\cline { 4 - 5 } & & & & \\
\cline { 4 - 5 } & & & &
\end{tabular}

The FE mesh was made up of 3D continuum elements with reduced integration (C3D20R). The piezo-electric element was meshed with 3D continuum with an additional electrical-potential variable (C3D20RE) ("Abaqus 6.14 User's Manual," 2016). To calculate eigenvalues of the transducer for characterising its modal frequencies and mode shapes, a linear permutation frequency step was incorporated after the static general step for applying a preload to the piezoelectric stack. To study distribution of the vibration response in the transducer, a harmonic analysis using a steady-state dynamics step was employed to extract vibration amplitudes and gain. To obtain the impedance spectrum $(Z)$ from the FE model, the following relation was used: 


$$
Z=\frac{V}{j \omega Q}
$$

where $V$ is the voltage across the piezoelectric rings, $Q$ is the total electrical reaction charge, $\omega$ is the angular frequency and $j=\sqrt{-1}$.

A general contact interaction, with a friction penalty in the tangential direction and hard contact in the normal direction, was assumed to represent contact between the parts of the assembled model. Boundary conditions in terms of the electrical potential for the piezoelectric rings were applied on both sides of each component.

A mesh-sensitivity study was carried out to ensure that all the predicted modes and modal frequencies in the frequency range of interest were accurate. The model with 23,000 elements offers a good balance between accuracy and computing time and was adopted for all the presented results.

\subsection{Characterisation of the ultrasonically assisted cutting device}

Based on the design, an ultrasonically assisted cutting device was manufactured and assembled (shown in Fig. 3). The pre-stressing of the device was performed by applying a torque of $60 \mathrm{Nm}$ to the central bolt. An impedance analyser was used to measure the resonant frequency and the maximum output amplitude under harmonic excitation. The test was conducted using an HP 4192A system which was capable of sweeping frequency from 5 $\mathrm{Hz}$ to $13 \mathrm{MHz}$ with a minimum resolution of $1 \mathrm{mHz}$. Here, the sweeping frequency was set from $22 \mathrm{kHz}$ to 26 $\mathrm{kHz}$ with a resolution of $10 \mathrm{~Hz}$.

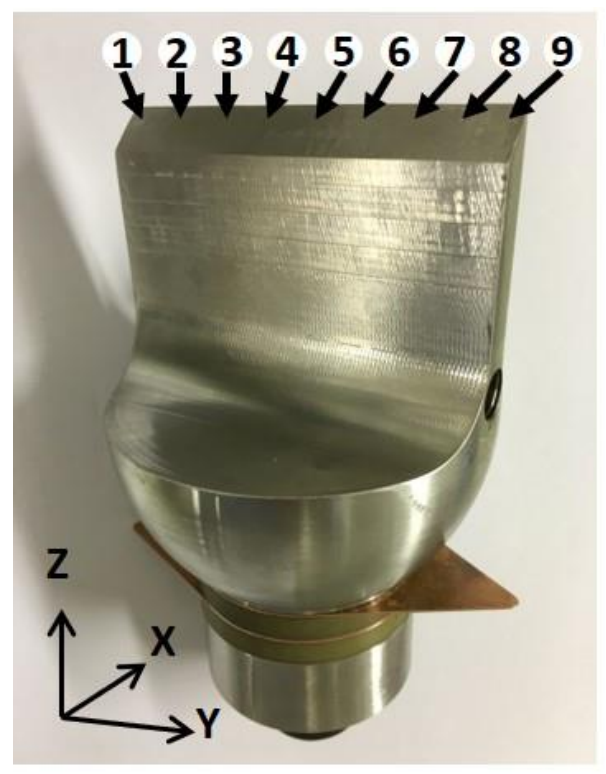

Fig. 3 Prototype of UACD

The vibration response of the device was measured with a laser doppler vibrometer (Polytec, OFV-3001), which was a well-established optical metrology tool to record surface velocity of vibrating objects. The device was driven by an ultrasonic generator (Beijing Ultrasonic Ltd) with the maximum power output at $1.2 \mathrm{~kW}$ and maximum current at $4.5 \mathrm{~A}$. The vibration amplitudes along the $\mathrm{z}$ axis were measured at 9 equidistant positions on 
the blade edge (locations 1 to 9 in Fig. 3). The amplitudes were monitored in a free-vibration mode at power output of $60 \mathrm{~W}$.

\subsection{Test rig design}

A Kistler 9257b piezo-multicomponent dynamometer was used to measure cutting forces along the cutting and orthogonal directions during the cutting process. The measuring range for the dynamometer is up to $\pm 5 \mathrm{kN}$ with a sensitivity of $-7.5 \mathrm{pC} / \mathrm{N}$ in the cutting direction (z-direction) and $-3.7 \mathrm{pC} / \mathrm{N}$ in the orthogonal directions. The force data measured were obtained using charge amplifiers (Kistler 5015A charge meter) followed by conversion through an analog-to-digital converter (digital oscilloscope Picoscope) connected to a computer. The acquired data were post processed in Matlab.

The test rig was capable of making multiple cuts with consistent section thickness at a constant feed rate. The design incorporates a stepper motor and an accurate lead screw in a slider. The stepper motor used was IGUS Nema 23 driven by a nanotech smcI36 driver, connected to a PC using a nanotech ZK-RS485-USB. The nanotech software was used to set the step size, step number and step frequency of the stepper motor. Based on the configurations of the slider, the software was used to create the clock pulses for the stepper motor to drive the cutting device at a constant feed rate. A sample for cutting was attached to the dynamometer for measuring cutting forces in both primary and orthogonal directions. The cutting device was held on a holder at its node points by bolts, which allow the device to rotate for changing the blade angle. The device holder was then slotted on to a base plate using a T-joint, moved horizontally with the use of the slider and the stepper motor (Fig. 4).

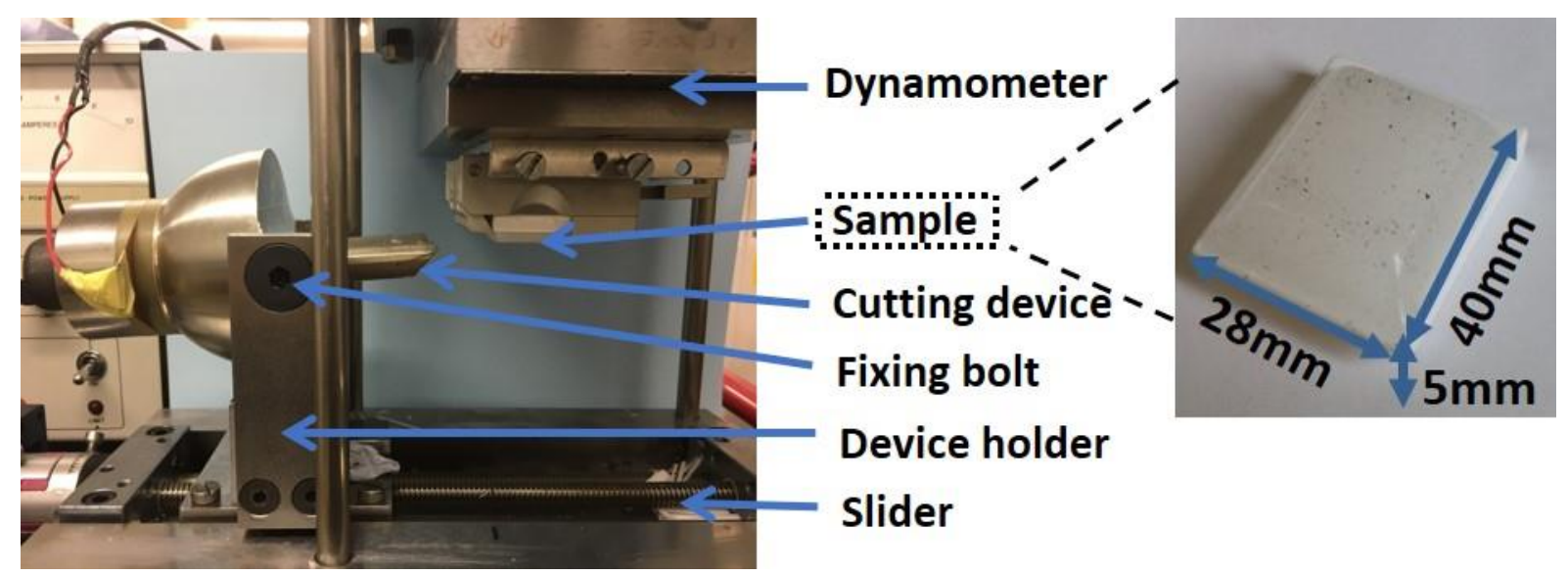

Fig. 4 Test rig used in experiments and wax block sample

\subsection{Experimental methodology}

Experimental tests were performed using wax blocks in an attempt to quantify the difference of cutting forces between UAC and CC. The test rig was set up for one wax sample to be cut multiple times. After completing the cuts, the sample and blade were replaced. The cutting speed and the blade angle ( $\gamma$ ) (Fig. 5) in the tests were 10 $\mathrm{mm} / \mathrm{s}$ and $25^{\circ}$, respectively, which is similar with the parameters used in microtome cutting by a histologist. Trial and error tests were taken to optimise the parameters based on the study by (Allison and Vincent, 1990). The UACD was then fixed on a microtome to perform both CC and UAC in production of thin sections. The setup is 
shown in Fig. 6. Due to the packaging constraints, the commercial microtome did not allow for the cutting forces to be measured but instead this system was used to inspect the quality of the sample after CC and UAC.

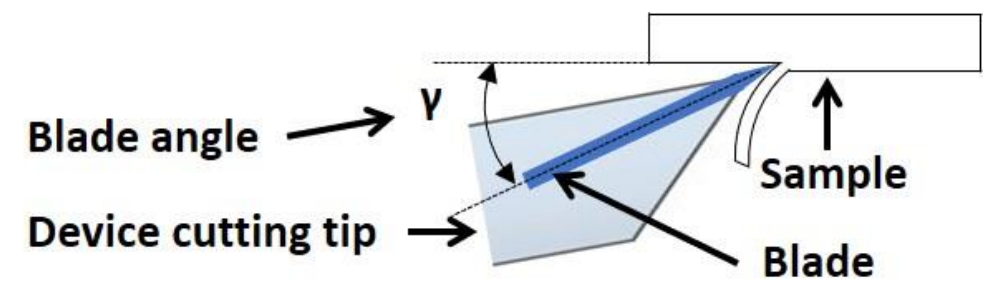

Fig. 5 Illustration of blade angle during cutting process

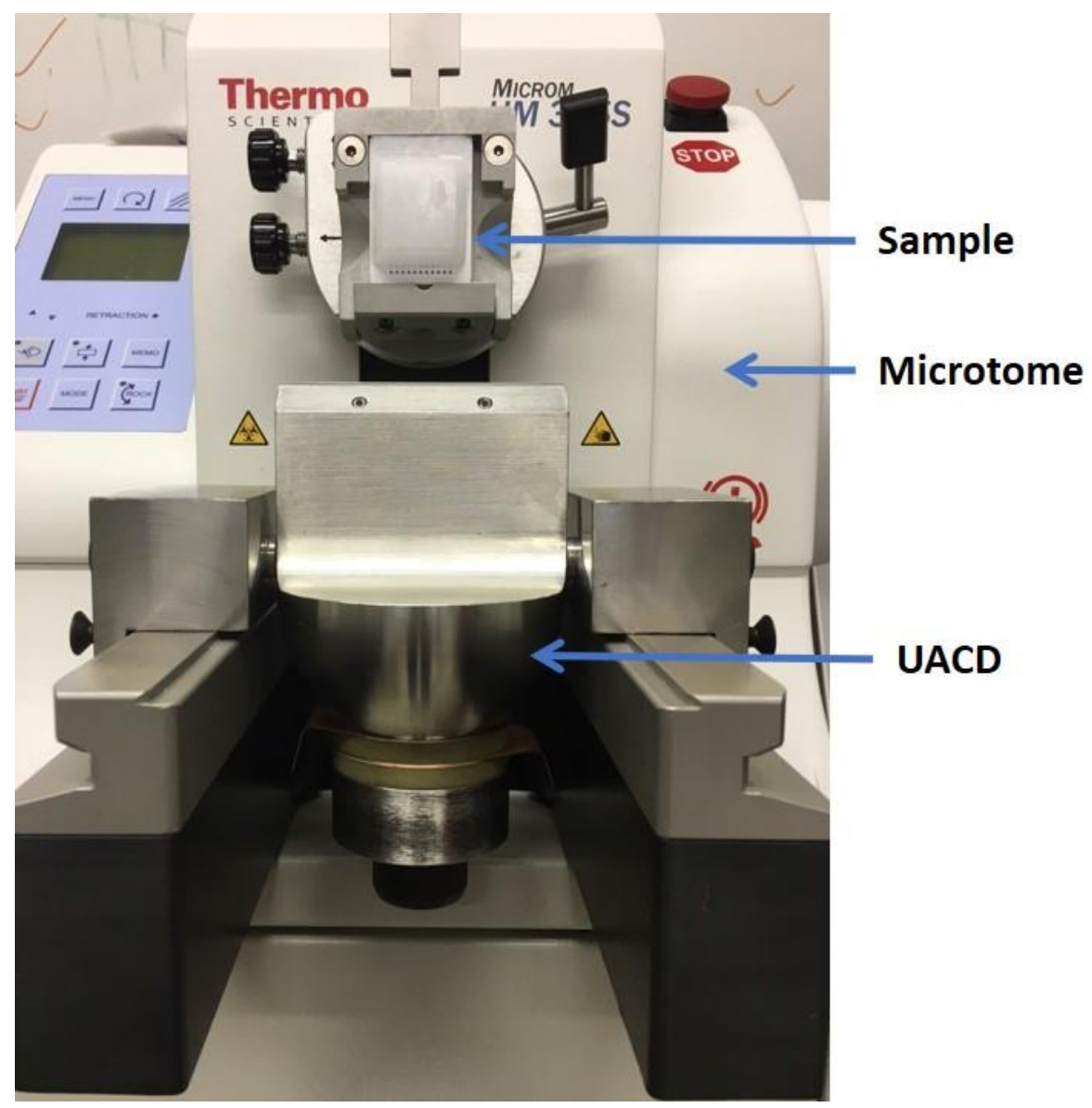

Fig. 6 Microtome setup for CC and UAC with microscope slide and stained bio-tissue section

Finally, samples of sheep heart tissue were processed and embedded in wax by the histologist, who created sections with a thickness of $4 \mu \mathrm{m}$ using the UACD fixed on the microtome in CC and UAC (Attached video 1 and 2). Staining of the samples (Fig. 7) after cutting was performed to reveal structural details under a Zeiss microscope at $50 \times$ magnification. 


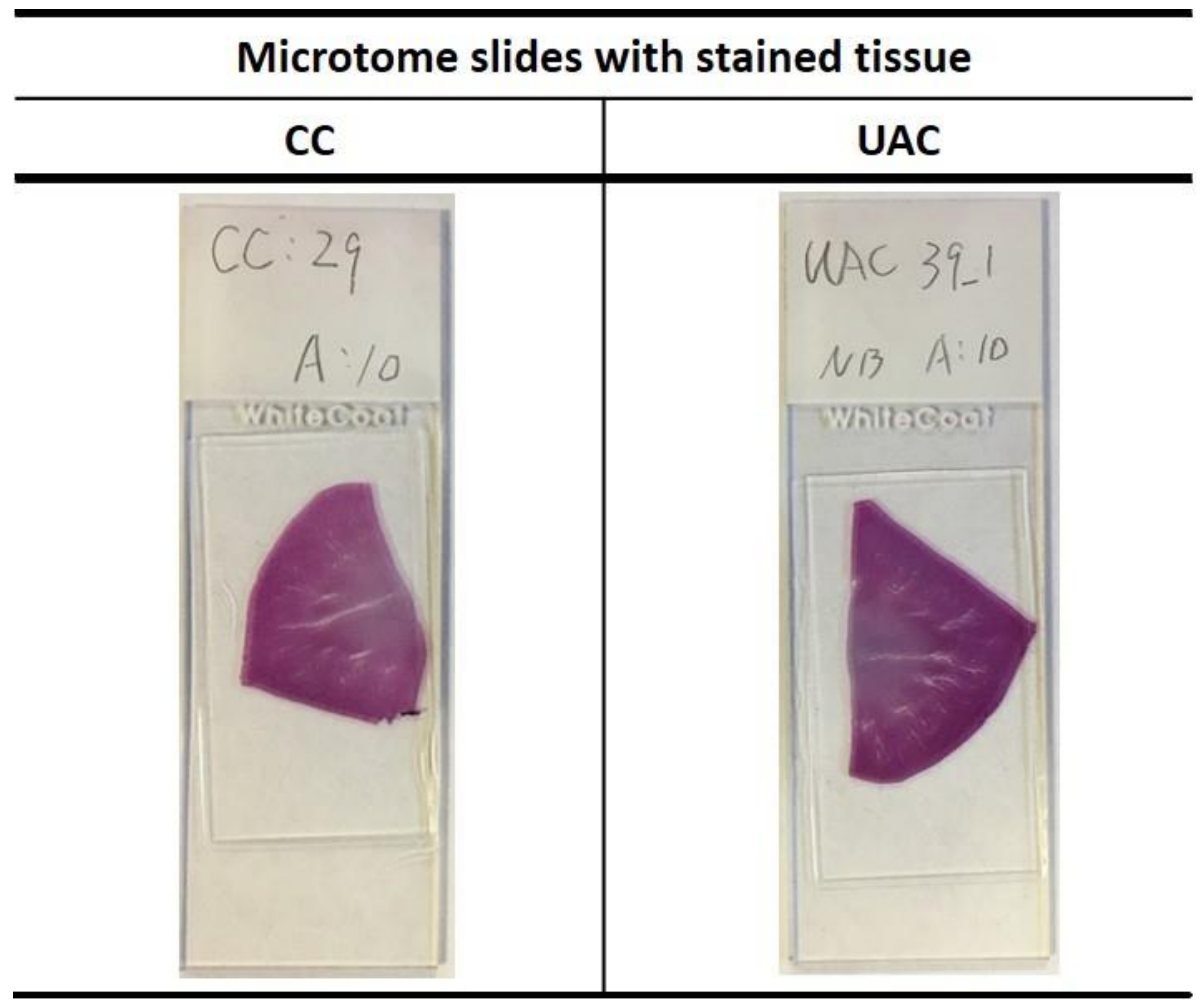

Fig. 7 Microtome slides with stained bio-tissue sections from CC and UAC

\subsection{Blade wear analysis}

Since cutting forces in production of thin sections are dominated by friction forces, coating a blade with PTFE (polytetrafluoroethylene) can reduce friction, allowing samples to be sectioned with ease. For our study, coated blades were used. The profile of a disposable blade cutting edge, used for the microtome cutting provided by Cellpath Ltd. UK, is shown in Fig. 8. The measurement confirmed three bevels on the cutting edge. Surface roughness of the third bevel, which is the primary cutting surface/edge, was measured using an Alicona

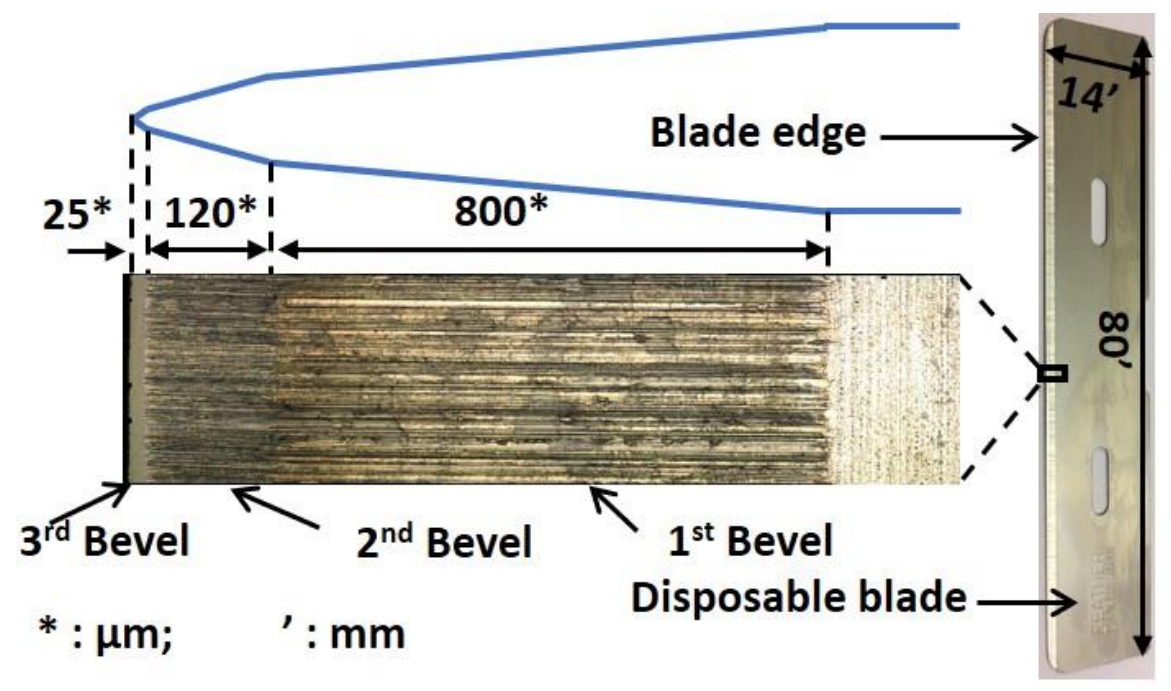

Fig. 8 Cutting edge of disposable blade 
InfiniteFocus microscope. As a result of the blade wear, scratches and nicks, the surface topography of the blade edge contains peaks and valleys, having a major influence on variation in the surface roughness parameter. The area parameter $S_{z}$ is defined as the sum of the largest peak's height value and largest valley's depth value within the sampling area, for description of amplitude-related properties of a surface (Blunt and Jiang, 2003). Typical applications for $S_{z}$ include characterisation of coating surfaces (Michigan Metrology LLC, 2019). The blade used in the tests were coated with PTFE; hence, $S_{z}$ was measured to quantify the surface roughness within the sampling area. These sampling areas were taken at three distinct points along the cutting edge, one in the centre of the edge and two points at $5 \mathrm{~mm}$ on either side of the center. To compare differences in blade wear between CC and UAC, consistent cutting tests were repeated up to 500 cuts with both cutting techniques.

To clearly present the experimental results, a table (Table 4) was created to show the information on the dependent and independent variables for each experiment.

Table 4 The dependent and independent variables for each experiment

\begin{tabular}{|c|c|c|}
\hline Experiment & Dependent variables & Independent variables \\
\hline Modal analysis of UACD & $\begin{array}{l}\text { Resonant frequency } \\
\text { Frequency separation }\end{array}$ & Frequency \\
\hline $\begin{array}{l}\text { Vibration amplitude } \\
\text { uniformity of UACD }\end{array}$ & $\begin{array}{c}\text { Normalised } \\
\text { displacement }\end{array}$ & Position \\
\hline $\begin{array}{l}\text { Measurement of } \\
\text { cutting force }\end{array}$ & $\begin{array}{c}\text { Force } \\
\text { Max force }\end{array}$ & $\begin{array}{c}\text { Cutting time } \\
\text { Cutting direction } \\
\text { Orthogonal direction } \\
\text { CC } \\
\text { UAC }\end{array}$ \\
\hline $\begin{array}{c}\text { Characterisation of } \\
\text { slide quality }\end{array}$ & $\begin{array}{c}\text { Defects (score lines and } \\
\text { tears) } \\
\text { Chatter lines } \\
\end{array}$ & $\begin{array}{c}\text { Number of cuts } \\
\text { CC } \\
\text { UAC } \\
\end{array}$ \\
\hline $\begin{array}{c}\text { Characterisation of } \\
\text { blade quality }\end{array}$ & $\begin{array}{c}\text { Surface roughness } \\
\text { Scratch } \\
\text { Nick }\end{array}$ & $\begin{array}{c}\text { Number of cuts } \\
\text { CC } \\
\text { UAC }\end{array}$ \\
\hline
\end{tabular}




\section{Results and Discussion}

\subsection{Vibration characteristics of ultrasonically assisted cutting device}

\subsubsection{Modal analysis and frequency separation}

Modal analysis of the designed UACD was carried out by extracting the modal frequencies and mode shapes. In FEA, the resonance frequency was $22.6 \mathrm{kHz}$ with the mode shape illustrated in Fig. 9. The longitudinal mode was the primary mode of vibration.

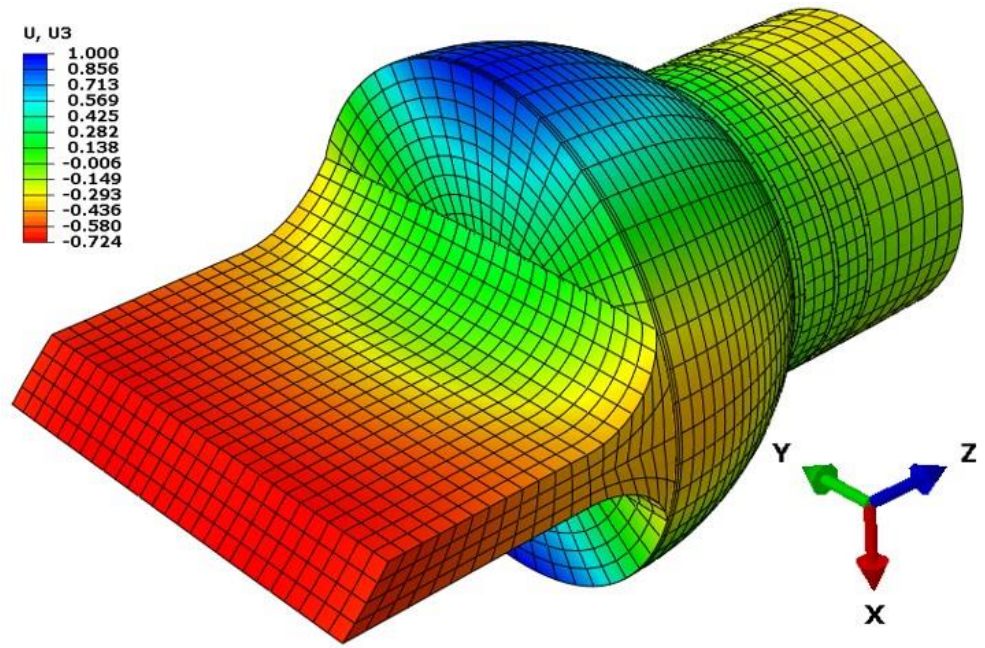

Fig. 9 Modal shape of UACD at $22.6 \mathrm{kHz}$, with U3 indicating normalised displacement in Z direction

Another FE model was created to simulate the real constrained condition of the UACD by applying the nodal points with fixed boundary condition. There was a shift found in the resonant frequency from $22.6 \mathrm{kHz}$ (free nodal points in the modal analysis FE model) to $24.0 \mathrm{kHz}$ (fixed nodal points in the constrained FE model). The impedance spectrum of the UACD fixed on the microtome was obtained using the impedance analyser. Fig. 10 shows the results from the measured and FEA data (Fig. 10). The measured resonant frequency of $23.7 \mathrm{kHz}$ was found to be in a reasonable agreement with the FEA results of $24.0 \mathrm{kHz}$. Sufficient mode separation was obtained over $1.8 \mathrm{kHz}$ in experiments. The FE simulation assumed a linear piezoelectric effect (Elhadrouz et al., 2006), and as such cannot match the real behaviour of the transducer particularly with regard to values of impedance. 


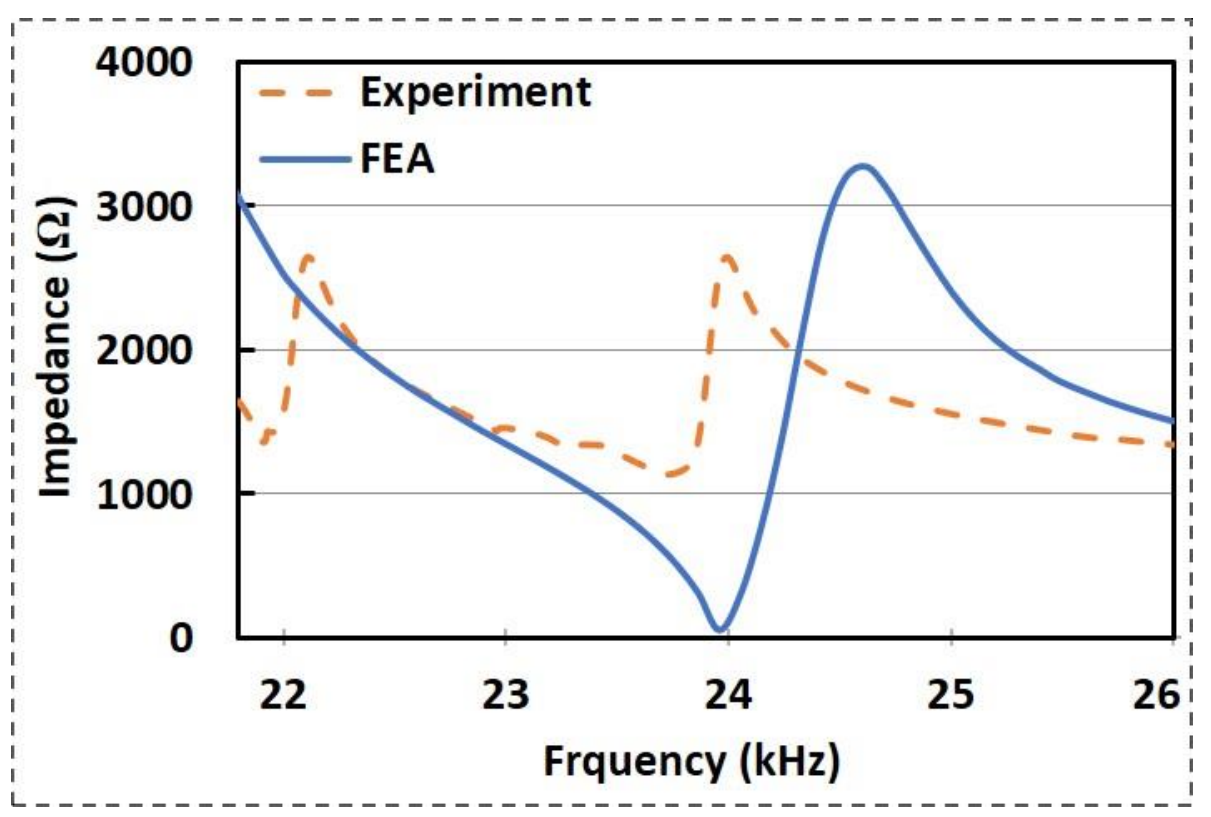

Fig. 10 Electrical impedance of UACD between $22 \mathrm{kHz}$ and $26 \mathrm{kHz}$ obtained by experiment and FEA

\subsubsection{Displacement analysis and gain}

Deformation in the longitudinal mode was assessed with numerical simulations. The amplitude of the displacement obtained along the holder's central line in the FE modal analysis is shown in Fig. 11. The maximum displacement was observed on the cutting edge of the holder and one nodal point was found near the blade-base region (see Fig 11). The chosen profile yielded a gain of 3.6, which was calculated by dividing the displacement at normalised position 1 (cutting edge) over that at normalised position 0 (rear surface).

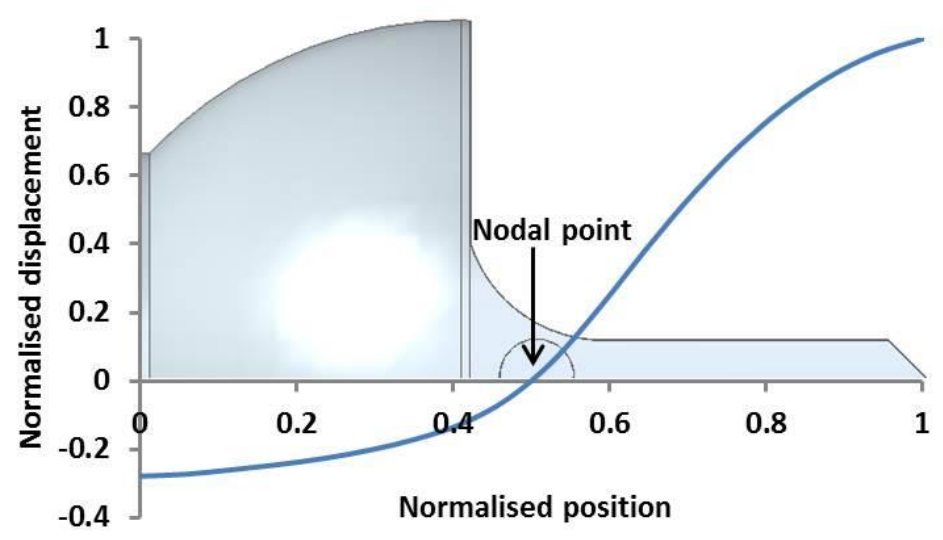

Fig. 11 Normalised displacement distribution along blade holder

\subsubsection{Amplitude uniformity}


To enable a high-quality cut using this device, uniformity of the vibration amplitude across the cutting edge is important to assess. The vibration amplitude uniformity is defined as $U_{d} / U_{D}$, where $U_{D}$ and $U_{d}$ are the maximum and minimum amplitudes of ultrasonic vibration at the cutting edge at a chosen temporal state, respectively. The variation on vibration amplitude (in normalised units) obtained from the numerical study is shown in Fig. 12. The

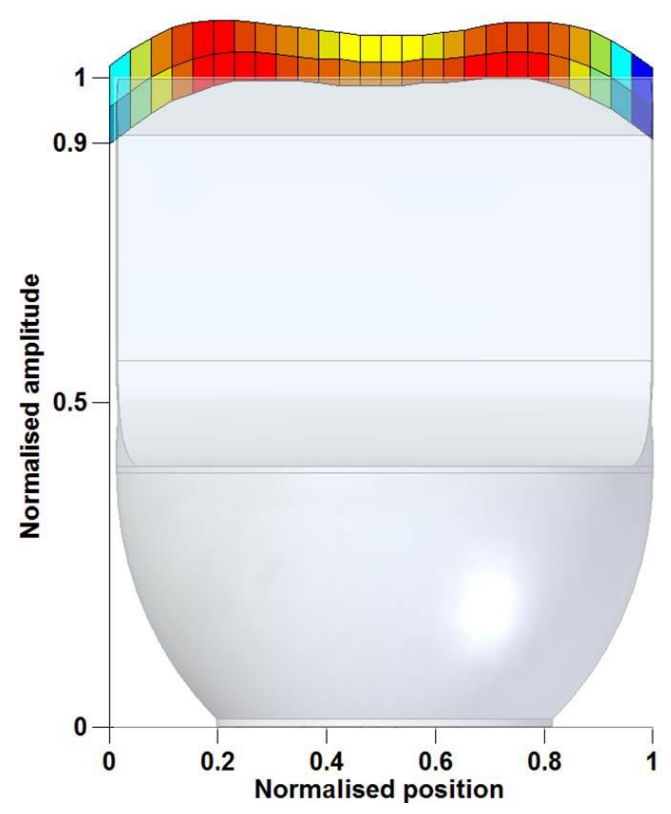

Fig. 12 Normalised amplitude distribution along cutting tip

FE results show a high level of uniformity of the cutting edge at $90 \%$.

The average vibration amplitude measured using the laser doppler vibrometer is $1.98 \mu \mathrm{m}$ at the operating frequency of $23.7 \mathrm{kHz}$. The normalised vibration amplitudes are presented in Fig. 13 demonstrating the uniformity

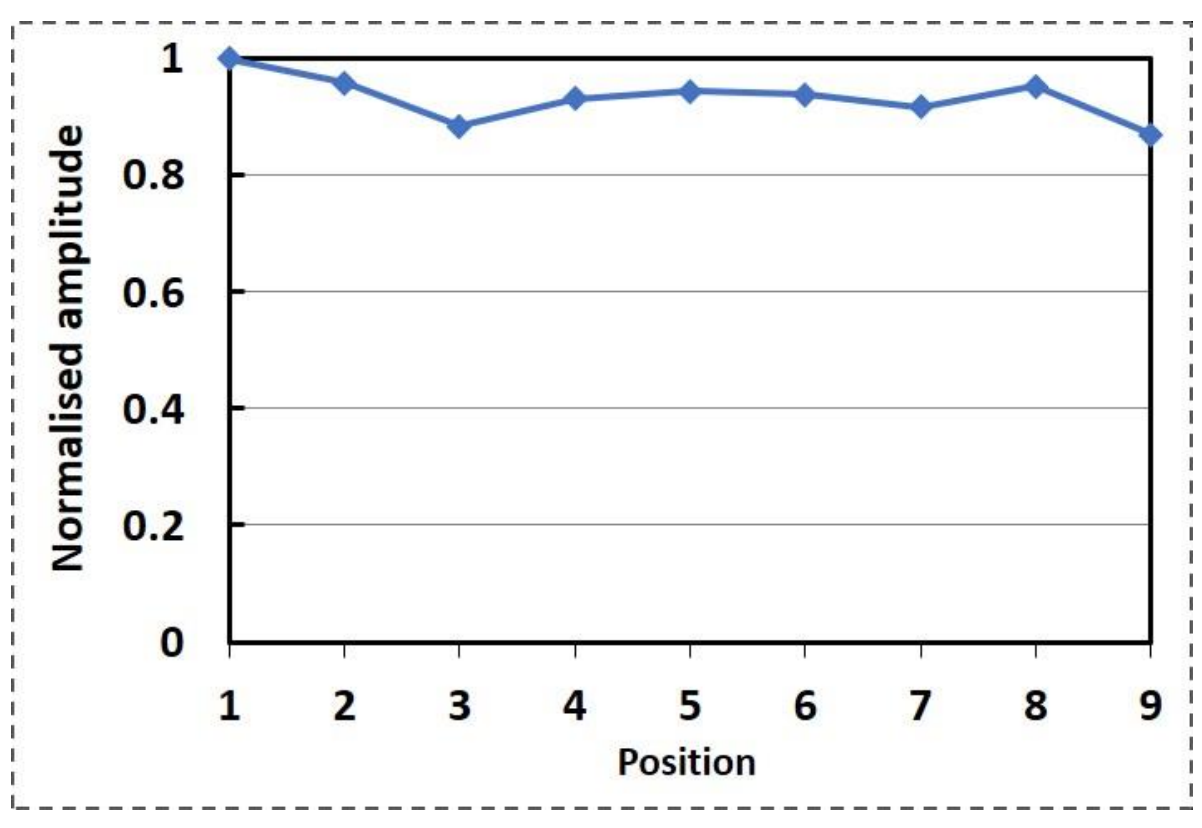

Fig. 13 Normalised amplitudes for comparison at various positions along cutting tip from experiment 
at $87 \%$ from the experiment. The value of uniformity from the measured amplitude is found to be in agreement with the FEA results.

\subsection{Experimental results for $\mathrm{CC}$ and $\mathrm{UAC}$}

A typical evolution of the cutting force in CC and UAC is shown in Fig. 14.

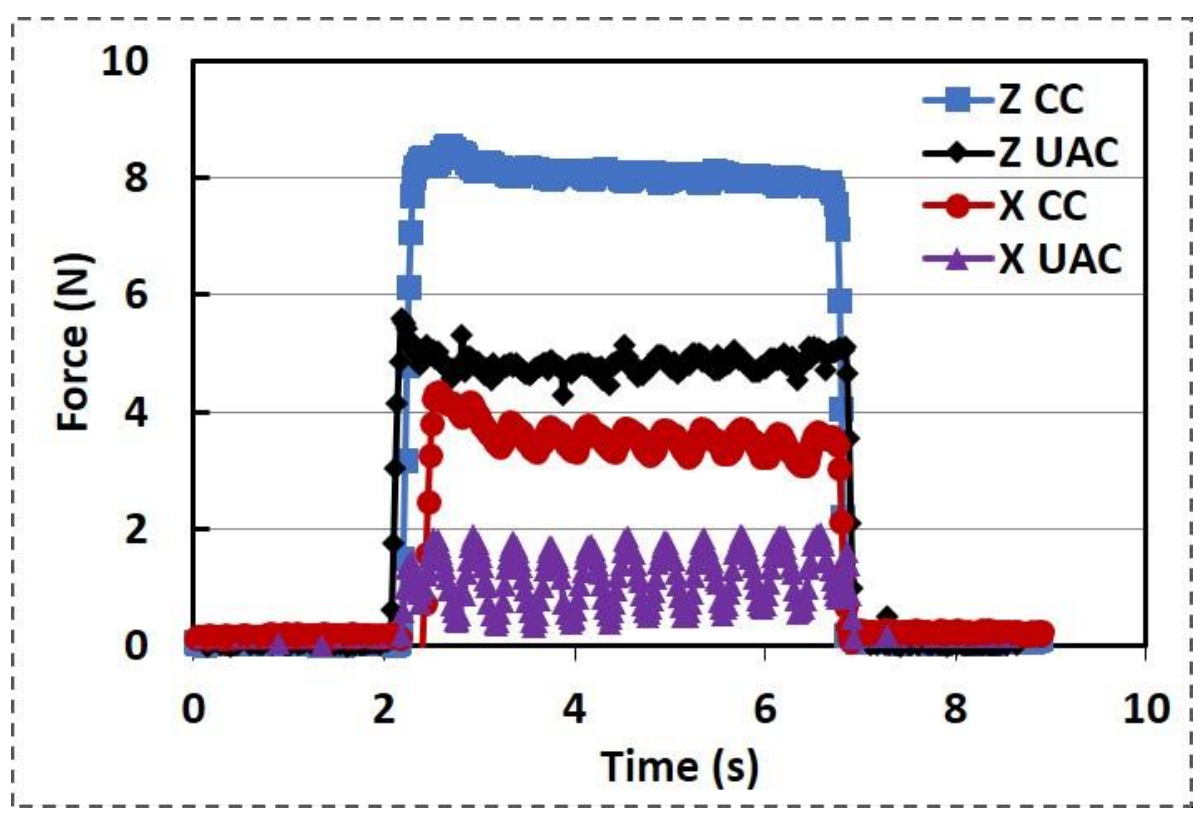

Fig. 14 Cutting force data for $\mathrm{CC}$ and $\mathrm{UAC}$ at primary cutting direction ( $\mathrm{Z}$ axis) and orthogonal direction (X axis)

The results demonstrate a considerable decrease in both the primary and orthogonal cutting forces for the ultrasonically assisted cuts. The experiment was repeated three times for consistency. All cuts demonstrated similar cutting trends for the forces. The average reductions of maximum forces (Fig. 15) were $33.5 \%$ in the primary cutting direction ( $\mathrm{Z}$ axis) and $52.6 \%$ in the orthogonal direction ( $\mathrm{X}$ axis). The maximum forces were

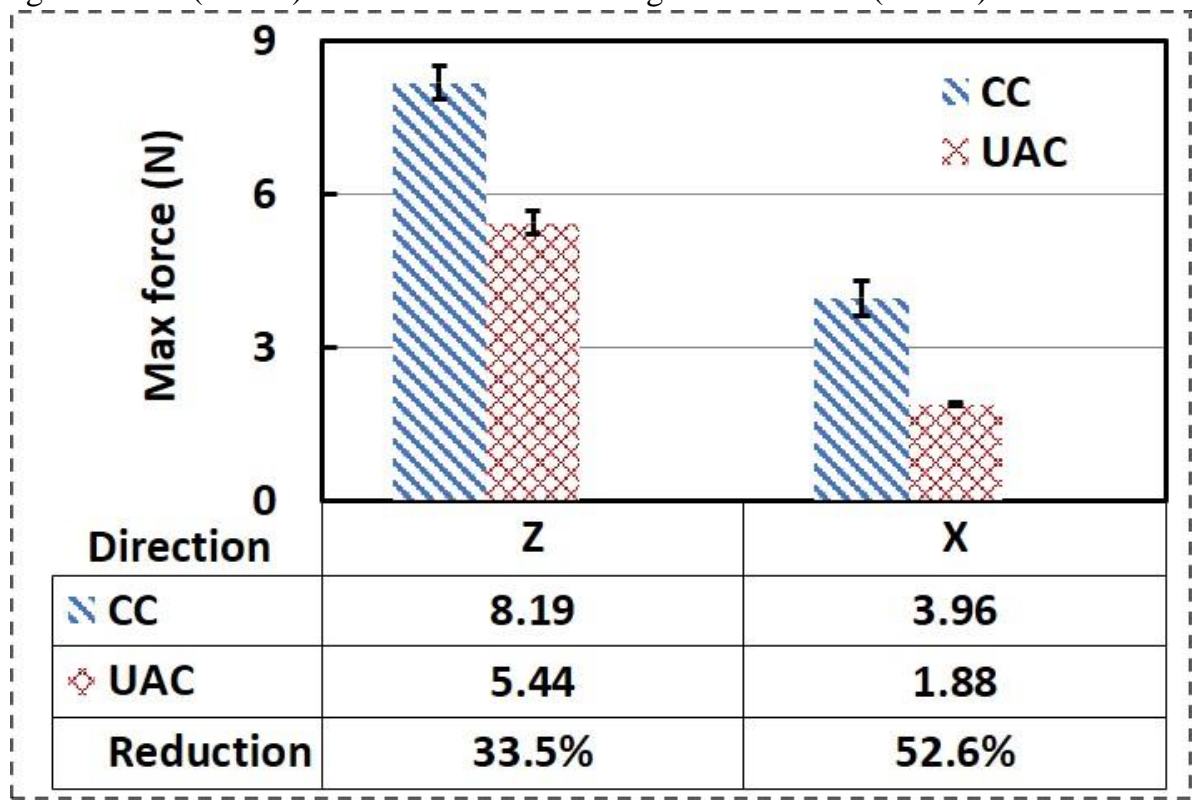

Fig. 15 Force-reduction data for $\mathrm{CC}$ and $\mathrm{UAC}$ at primary cutting direction ( $\mathrm{Z}$ axis) and orthogonal direction (X axis) 
comparitevly assessed as this is the peak force imposed on the cutting sample. Apparently, the nominal force in UAC was considerably lower than this value.

Ribbons of wax were cut with both CC and UAC from the microtome setup (Fig. 16). The continuous ribbons had no attachment with the block and no defects caused by excessive compression and sereve score and chatter lines were found from the sections. In general, they were considered as high-quality sections. The experimental results for UAC demonstrated the ability of ultrasonically assisted cutting to provide consistent and reliable thin sections for microtomy.

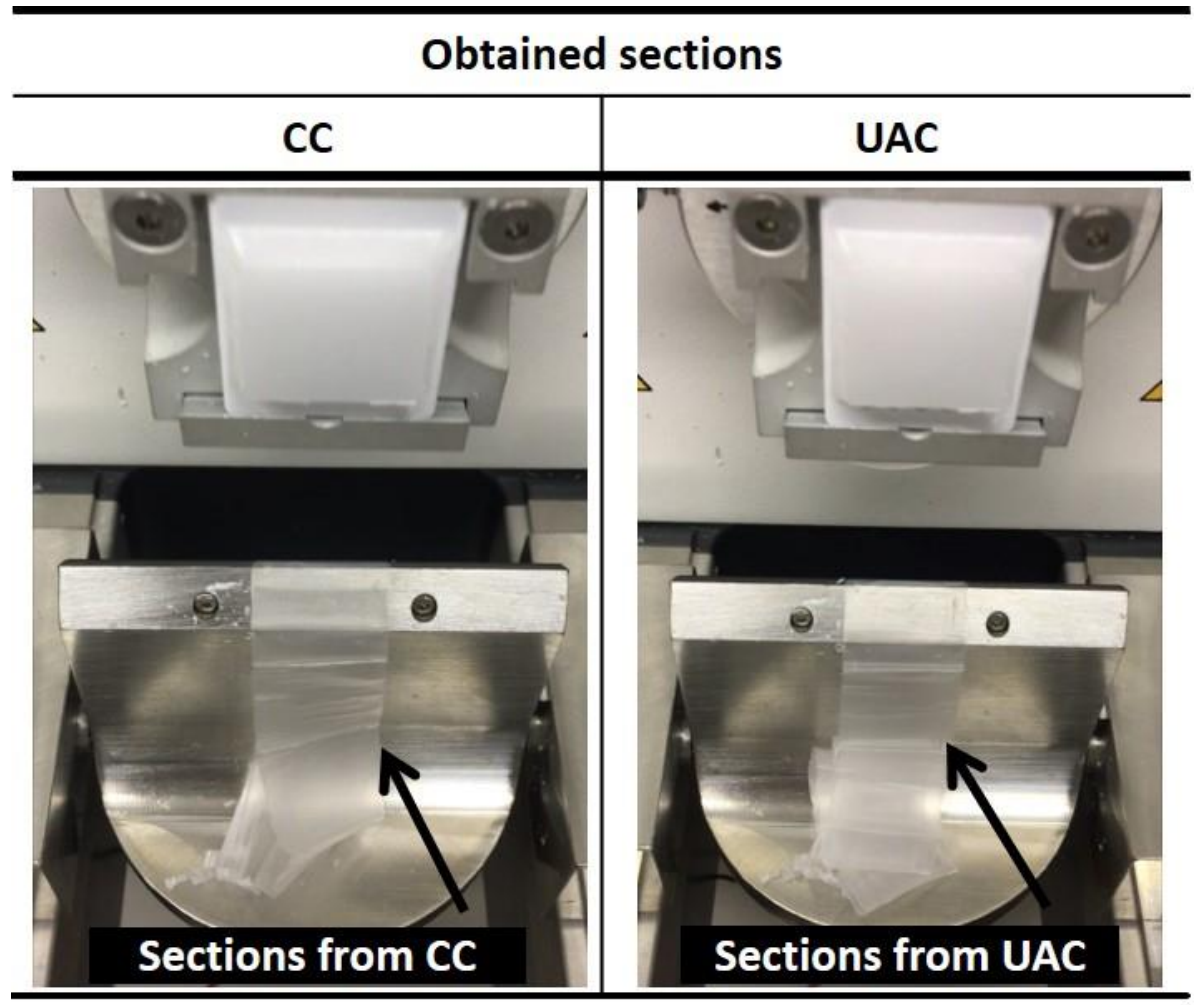

Fig. 16 Sections obtained with microtome setup in CC and UAC

\subsubsection{Characterisation of slide quality}

To identify the effect of UAC on section quality of biological tissues, slides were created with the sheep-heart tissue samples after a large number of cuts - up to 500 - for CC and UAC. The slide quality for CC and UAC were examined from their microscopic images. Most slides were cut automatically with the microtome for both $\mathrm{CC}$ and UAC. At selected moments after a set number of cuts, sections were cut manually for microscopic examination. Usually, the manual cuts were taken from the last 5 cuts of the selected moments (100, 250, 300, and 500 cuts in this study). Since not every slide was examined, only a range of cuts could be inferred corresponding to damage initiation. 
Initially, defects were found easily after 250 conventional cuts (Fig. 17): there was a scoreline with length over 6 $\mathrm{mm}$ in the CC slide after 250 cuts but none was observed in those of UAC even after 500 cuts - only faint chatter

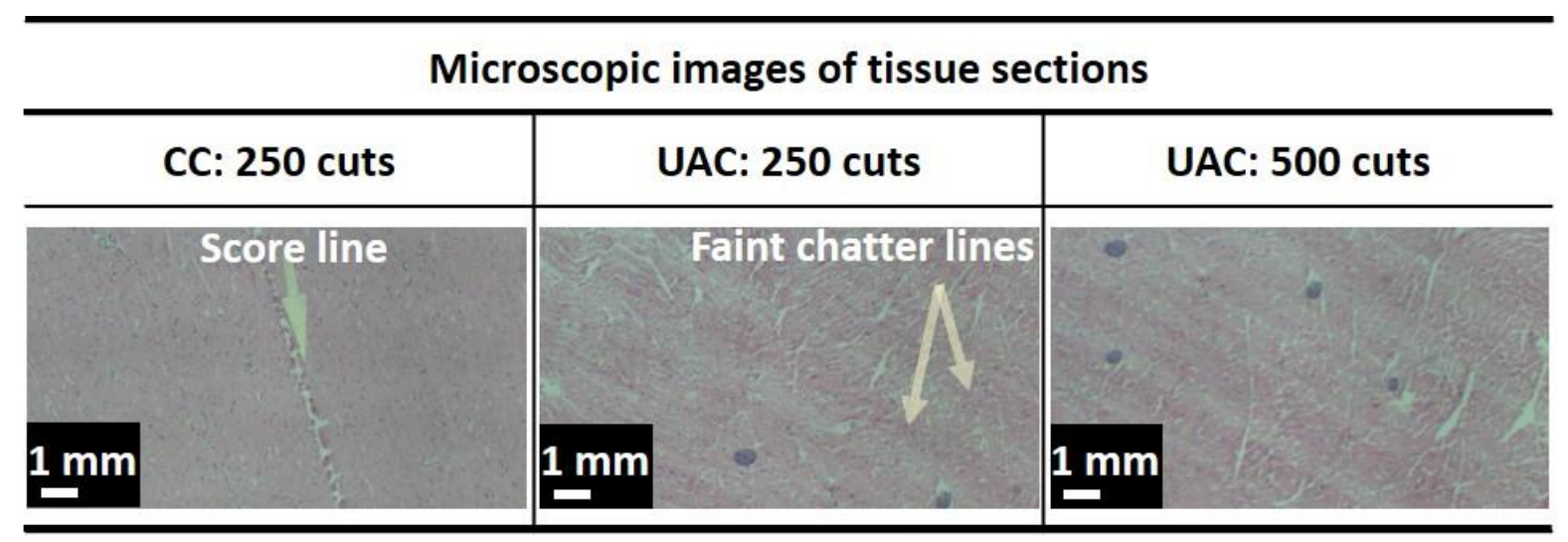

Fig. 17 Microscopic images of sections after 250 cuts for both CC and UAC and 500 cuts for UAC

lines (fringes). This indicates that in CC the blade suffers a greater amount of damage when compared to UAC. 
Additional sections were obtained from another set of experiment (Figure 18) showing some magnified details. From the microscopic images, significant tearing was observed in CC slides, espically after 300 cuts. In contrast, slides produced with UAC after 100 and 300 cuts did not show any significant tearing or damage. The increased tearing in $\mathrm{CC}$ was likely due to increased cutting forces. As a result of the blade vibration in UAC, faint ripple-

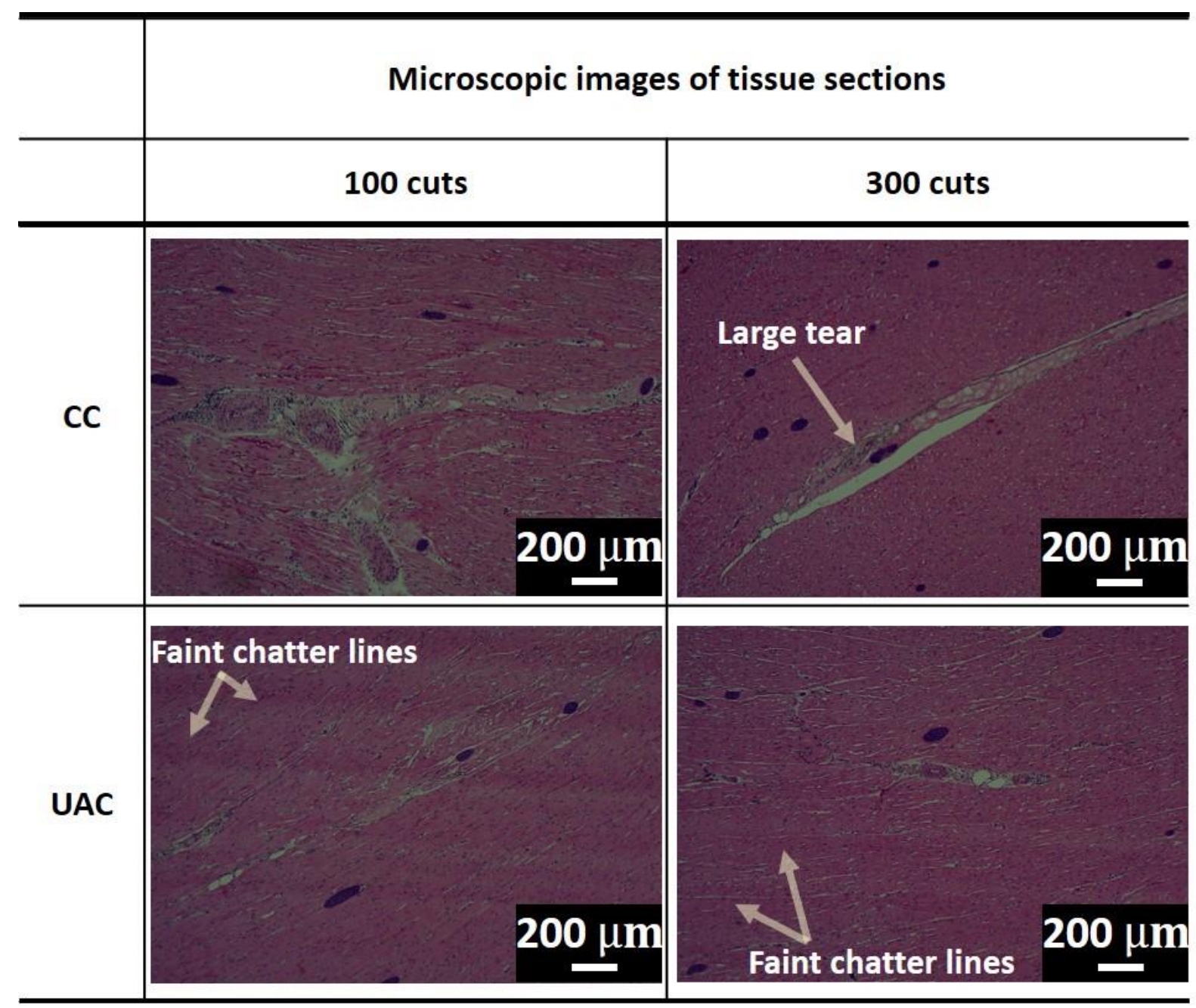

Fig. 18 Microscopic images showing section quality of CC and UAC in a finer scale

like periodic fringes (chatter lines) were observed in UAC samples. These features, though not desirable, do not hinder the histological assessment.

\subsubsection{Characterisation of blade quality}


Additionally, surface roughness measurements were carried out on the edge of the blade after cuts produced with the two studied techniques. The area surface-roughness parameter $S_{z}$ for the maximum height of the sampling surface was used to quantify the blade quality (Fig. 19). Typical sampling areas for the roughness measurements

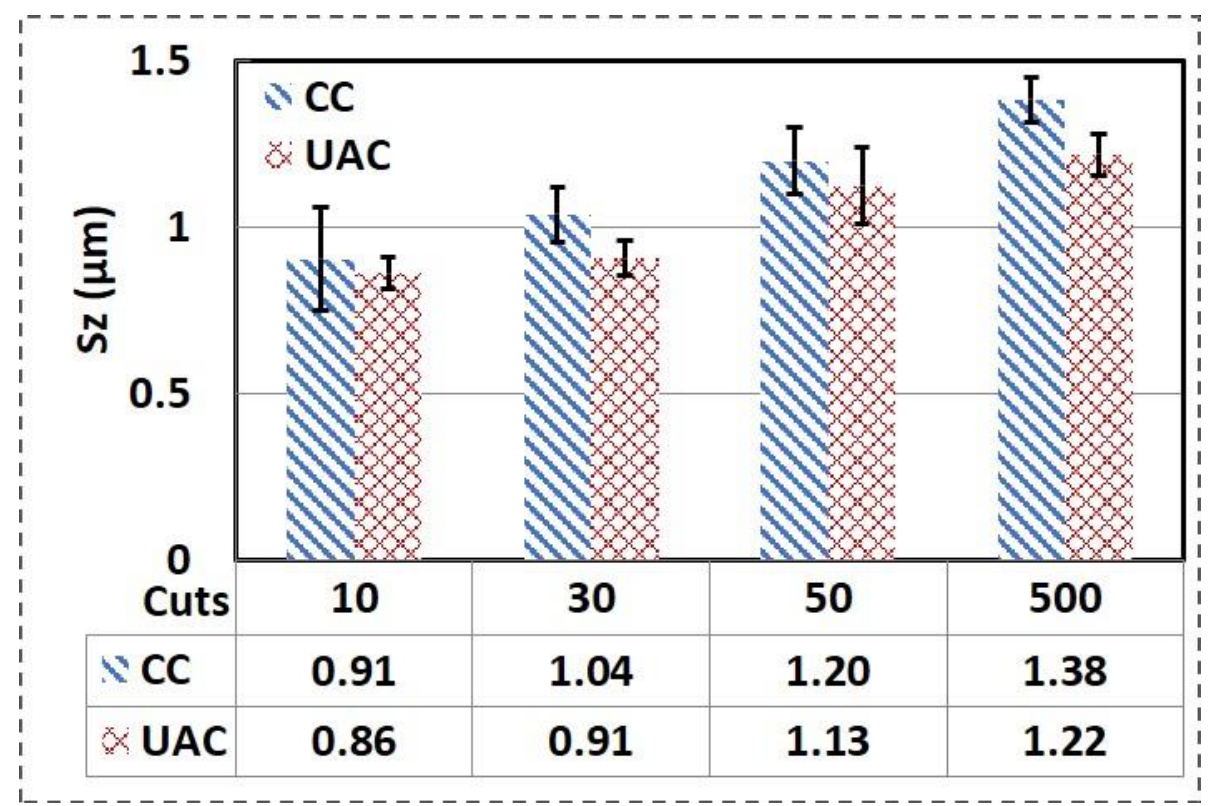

Fig. 19 Surface roughness parameter $S_{z}$ obtained from CC and UAC after 10, 30, 50 and 500 cuts

were shown in Fig. 20. A decreased level of wear in UAC was observed when compared to CC (Figs. 19 and 20). It was clear that the increased number of cuts led to an increase in wear in both UAC and CC. The average magnitude of $S_{z}$ after 500 cuts in UAC was $1.22 \mu \mathrm{m}$, which is a little bit larger than the average value of $S_{z}$ after 50 cuts in $\mathrm{CC}, 1.20 \mu \mathrm{m}$.

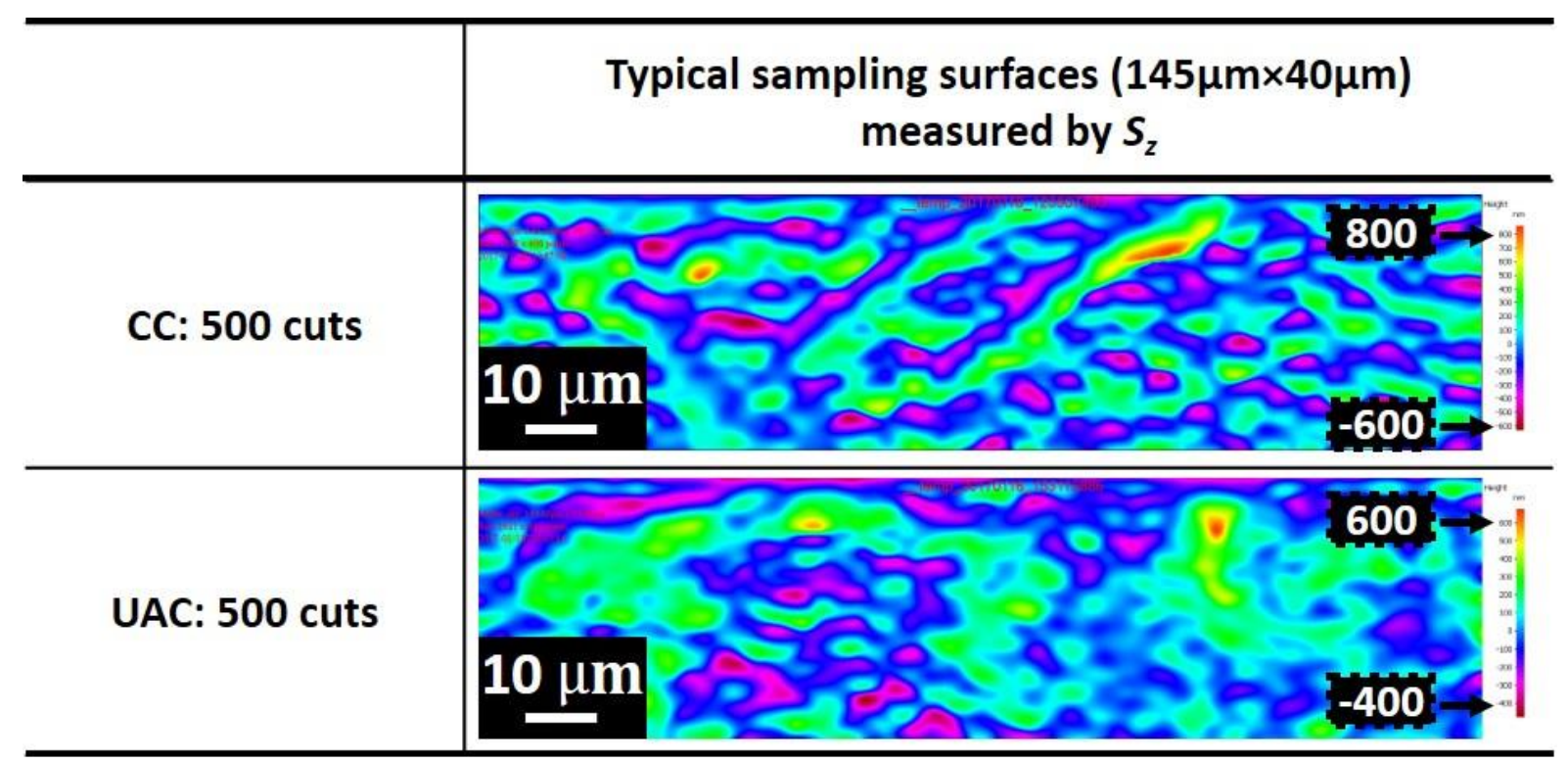

Fig. 20 Measured $S_{z}$ for typical sampling surfaces $(145 \mu \mathrm{m} \times 40 \mu \mathrm{m})$ of blade edge after 500 cuts with CC and UAC 
Finally, there were nicks and scratches found from the blade edge of CC after 250 cuts. The damaged blade probably made the scoreline on the sections. In comparison, the blade edge of UAC after 500 cuts was still in good condition with scratches observed under the microscope (Fig. 21). This indicates that the life of blade could

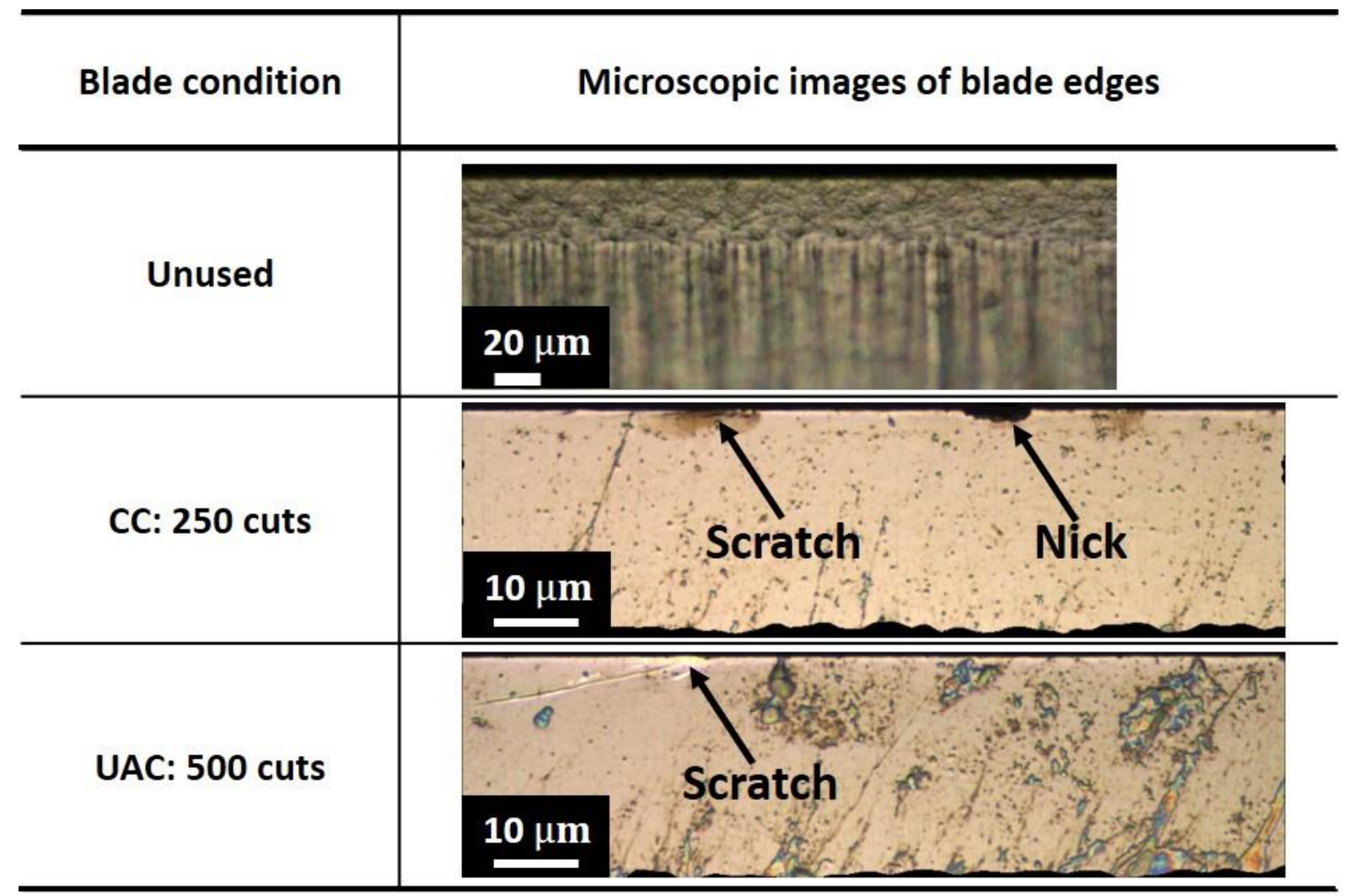

Fig. 21 Microscopic images obtained from blade edges for 0 and 250 cuts in CC and 500 cuts in UAC

be potentially extended in UAC when compared to $\mathrm{CC}$ for cutting bio-tissue sections.

\section{Concluding remarks}

- A novel ultrasonically assisted cutting device was developed for cutting thin sections of biological tissues. The manufactured prototype demonstrated for the first time the possibility of introducing cutting with ultrasonic assistance in a microtome.

- The results detailed in this work show that design and manufacture of microtomes with an ultrasonically assisted cutting device is possible in yielding high-quality bio-tissue sections with thickness of $4 \mu \mathrm{m}$, with reduction in cutting forces and diminished blade wear and damage. It improves the cutting process by promoting smooth section/ribbon generation with improved removal. This is further verified with a decrease in tears or score lines created within the sections of the ultrasonic cut samples.

- The design proposed allows for easy integration into existing microtome, which make it attractive for histologists as an alternative to traditional sample preparation techniques. 
- One of the biggest benefits of the UACD is that it improves longevity of disposable blades thus allowing for lower costs as well as decreasing the environmental footprint of microtome industry.

\section{Acknowledgements}

The authors gratefully acknowledge the funding provided by the Innovate UK (Project reference: 101863). Assistance of Neil Haine, Hannah Neesam and Colin Brewer from CellPath Ltd. UK with the experimental studies is sincerely acknowledged.

\section{Reference}

Abaqus 6.14 User's Manual, 2016.

Allison, R.T., Vincent, J.F. V, 1990. Measuring the forces acting during microtomy by the use of load cells. J. Microsc. 159, 203-210. https://doi.org/10.1111/j.1365-2818.1990.tb04776.x

Bancroft, J.D., Gamble, M., 2008. Theory and Practice of Histological Techniques.6th edition, Churchill Livingstone Elsevier.

Blunt, L., Jiang, X., 2003. 9 - Applications of Numerical Parameters and Filtration, in: Blunt, L., Jiang, X. (Eds.), Advanced Techniques for Assessment Surface Topography. Kogan Page Science, Oxford, pp. 221-247. https://doi.org/https://doi.org/10.1016/B978$190399611-9 / 50009-8$

Cardoni, A., MacBeath, A., Lucas, M., 2006. Methods for reducing cutting temperature in ultrasonic cutting of bone. Ultrasonics. https://doi.org/10.1016/j.ultras.2006.06.046

Elhadrouz, M., Ben Zineb, T., Patoor, E., 2006. Finite element analysis of a multilayer piezoelectric actuator taking into account the ferroelectric and ferroelastic behaviors. Int. J. Eng. Sci. https://doi.org/10.1016/j.ijengsci.2006.05.013

Grand View Research, 2017. Microtome market analysis by product, by technology, by region, and segment forecasts $2018-2025$.

Hopwood, N., 2000. Producing Development: The Anatomy of Human Embryos and the Norms of Wilhelm His, Bulletin of the history of medicine. https://doi.org/10.1353/bhm.2000.0020

Kapelsohn, K., 2015. Improved Methods for Cutting, Mounting, and Staining Tissue for Neural Histology.

Liao, Z., Axinte, D.A., 2016. On chip formation mechanism in orthogonal cutting of bone. Int. J. Mach. Tools Manuf. https://doi.org/10.1016/j.ijmachtools.2015.12.004

Ma, C., Shamoto, E., Moriwaki, T., Wang, L., 2004. Study of machining accuracy in ultrasonic elliptical vibration cutting. Int. J. Mach. Tools Manuf. https://doi.org/10.1016/j.ijmachtools.2004.04.014

Merchant, M.E., 1945. Mechanics of the metal cutting process. I. Orthogonal cutting and a type 2 chip. J. Appl. Phys. https://doi.org/10.1063/1.1707586

Michigan Metrology LLC, 2019. 3D Surface Roughness and Wear Measurement Analysis and Inspection [WWW Document]. URL https://www.michmet.com/3d_s_height_parameters.htm (accessed 6.12.19).

Mohammed, F., Thapasum Fairozekhan, A., Mohamed, S., 2012. Microtomes and Microtome Knives - A Review and Proposed Classification, Annal Dent Univ Malaya. 
Nath, C., Rahman, M., 2008. Effect of machining parameters in ultrasonic vibration cutting. Int. J. Mach. Tools Manuf. https://doi.org/10.1016/j.jimachtools.2008.01.013

Piezoelectric ceramics [WWW Document], 2016. URL www.morgantechnicalceramics.com (accessed 6.26.16).

Reilly, G.A., McCormack, B.A.O., Taylor, D., 2004. Cutting sharpness measurement: A critical review. J. Mater. Process. Technol. https://doi.org/10.1016/j.jmatprotec.2004.04.297

Sinn, G., Zettl, B., Mayer, H., Stanzl-Tschegg, S., 2005. Ultrasonic-assisted cutting of wood. J. Mater. Process. Technol. https://doi.org/10.1016/j.jmatprotec.2005.04.076

Williams, J.G., Patel, Y., 2016. Fundamentals of cutting. Interface Focus. https://doi.org/10.1098/rsfs.2015.0108

WILLIS, A., VINCENT, J.F.V., 1995. Monitoring cutting forces with an instrumented histological microtome. J. Microsc. https://doi.org/10.1111/j.1365-2818.1995.tb03581.x

Zhang, J., Cui, T., Ge, C., Sui, Y., Yang, H., 2016. Review of micro/nano machining by utilizing elliptical vibration cutting. Int. J. Mach. Tools Manuf. https://doi.org/10.1016/j.ijmachtools.2016.04.008

Zhou, M., Ngoi, B.K.A., Yusoff, M.N., Wang, X.J., 2006. Tool wear and surface finish in diamond cutting of optical glass. J. Mater. Process. Technol. https://doi.org/10.1016/j.jmatprotec.2005.02.248 
Table 1 The dimensions of the UACD in units of $\mathrm{mm}$ and degree for angles

\begin{tabular}{|c|c|c|c|c|c|c|c|c|c|c|c|c|c|c|c|}
\hline \multirow{2}{*}{\multicolumn{2}{|c|}{$\begin{array}{l}\text { Back } \\
\text { mass }\end{array}$}} & \multirow{2}{*}{\multicolumn{2}{|c|}{ Piezo-ring }} & \multirow{2}{*}{\multicolumn{3}{|c|}{ Electrode }} & \multicolumn{9}{|c|}{ Front mass } \\
\hline & & & & & & & \multicolumn{3}{|c|}{ Holder base } & \multirow{2}{*}{$\begin{array}{c}\text { Tapered } \\
\mathrm{I}_{4}\end{array}$} & \multirow{2}{*}{$\frac{\text { Body }}{I_{5}}$} & \multicolumn{3}{|c|}{ Cutting tip } & \multirow{2}{*}{$\begin{array}{c}\text { Slot } \\
\beta\end{array}$} \\
\hline $\mathrm{I}_{1}$ & $d_{1}$ & $t_{p}$ & $d_{1}$ & $\mathrm{I}_{2}$ & $t_{e}$ & $\mathrm{~d}_{1}$ & $\mathrm{I}_{3}$ & $d_{1}$ & $d_{2}$ & & & $I_{6}$ & $t_{1}$ & $\alpha$ & \\
\hline 20 & 50 & 6 & 50 & 13 & 0.5 & 50 & 40 & 50 & 80 & 15 & 32 & 8 & 8 & 45 & 15 \\
\hline
\end{tabular}

\begin{tabular}{c|c|c|c}
\hline Length & Diameter & Thickness & Angle \\
\hline $\mathrm{I}_{*}$ & $\mathrm{~d}_{*}$ & $\mathbf{t}_{*}$ & $\boldsymbol{\alpha}, \boldsymbol{\beta}$ \\
\hline
\end{tabular}

Table 2 Materials properties used in FEM

\begin{tabular}{c|c|c|c|c|c}
\hline Parts & Materials & $\begin{array}{c}\text { Density } \\
\mathbf{( k g / \mathbf { m } ^ { 3 } )}\end{array}$ & $\begin{array}{c}\text { Young's } \\
\text { modulus } \\
\mathbf{( G P a )}\end{array}$ & $\begin{array}{c}\text { Poisson's } \\
\text { ratio }\end{array}$ & $\begin{array}{c}\text { Electrical } \\
\text { conductivity } \\
\mathbf{( S / m )}\end{array}$ \\
\hline $\begin{array}{c}\text { Front \& back } \\
\text { masses }\end{array}$ & $\begin{array}{c}\text { Stainless } \\
\text { steel }\end{array}$ & 7900 & 193 & 0.25 & - \\
\hline Central bolt & Steel & 7850 & 200 & 0.33 & - \\
\hline Electrodes & Copper & 8960 & 120 & 0.34 & $5.96 \times 10^{7}$ \\
\hline
\end{tabular}

Table 3 Properties of piezoelectric ceramic rings (PZT401) used in FEM ("Piezoelectric ceramics," 2016)

\begin{tabular}{c|c|c|c|c}
\hline Properties & Specification & Unit & Symbol & Value \\
\hline Mechanical & Density & $\mathrm{kg} / \mathrm{m}^{3}$ & $\rho$ & 7600 \\
\hline
\end{tabular}




\begin{tabular}{|c|c|c|c|c|}
\hline & Poisson's ratio & - & $\sigma$ & 0.31 \\
\hline & \multirow{2}{*}{ Compliances } & \multirow{2}{*}{$\mathrm{m}^{2} / \mathrm{N}$} & $S_{33}^{E}$ & $15.6 \times 10^{-12}$ \\
\hline & & & $S_{11}^{E}$ & $12.7 \times 10^{-12}$ \\
\hline Dielectric & Dielectric constant & - & $\varepsilon_{33}^{T} \cdot \varepsilon_{0}^{-1}$ & 1395 \\
\hline \multirow{3}{*}{ Piezoelectric } & \multirow{3}{*}{ Charge constants } & \multirow{3}{*}{$\mathrm{C} / \mathrm{N}$} & $d_{33}$ & $315 \times 10^{-12}$ \\
\hline & & & $d_{31}$ & $-132 \times 10^{-12}$ \\
\hline & & & $d_{15}$ & $511 \times 10^{-12}$ \\
\hline
\end{tabular}

Table 4 The dependent and independent variables for each experiment

\begin{tabular}{|c|c|c|}
\hline Experiment & Dependent variables & Independent variables \\
\hline Modal analysis of UACD & $\begin{array}{l}\text { Resonant frequency } \\
\text { Frequency separation }\end{array}$ & Frequency \\
\hline $\begin{array}{l}\text { Vibration amplitude } \\
\text { uniformity of UACD }\end{array}$ & Normalised displacement & Position \\
\hline $\begin{array}{l}\text { Measurement of cutting } \\
\text { force }\end{array}$ & $\begin{array}{c}\text { Force } \\
\text { Max force }\end{array}$ & $\begin{array}{c}\text { Cutting time } \\
\text { Cutting direction } \\
\text { Orthogonal direction } \\
\text { CC } \\
\text { UAC }\end{array}$ \\
\hline $\begin{array}{l}\text { Characterisation of slide } \\
\text { quality }\end{array}$ & $\begin{array}{c}\text { Defects (score lines and } \\
\text { tears) } \\
\text { Chatter lines }\end{array}$ & $\begin{array}{c}\text { Number of cuts } \\
\text { CC } \\
\text { UAC } \\
\end{array}$ \\
\hline $\begin{array}{l}\text { Characterisation of blade } \\
\text { quality }\end{array}$ & $\begin{array}{l}\text { Surface roughness } \\
\text { Scratch } \\
\text { Nick } \\
\end{array}$ & $\begin{array}{c}\text { Number of cuts } \\
\text { CC } \\
\text { UAC } \\
\end{array}$ \\
\hline
\end{tabular}


Supplement

\begin{tabular}{|c|c|c|c|c|c|}
\hline Equipment & Manufacturer/Model & \multicolumn{2}{|c|}{ Parameters } & Values & Units \\
\hline \multirow{2}{*}{$\begin{array}{l}\text { Impedance } \\
\text { analyser }\end{array}$} & \multirow{2}{*}{ HP 4192A } & \multicolumn{2}{|c|}{ Frequency range } & $5-13 \mathrm{M}$ & $\mathrm{Hz}$ \\
\hline & & \multicolumn{2}{|c|}{ Resolution } & 5 & $\mathrm{mHz}$ \\
\hline \multirow{2}{*}{$\begin{array}{l}\text { Ultrasonic } \\
\text { generator }\end{array}$} & \multirow{2}{*}{ Beijing Ultrasonic Ltd. } & \multicolumn{2}{|c|}{ Max power } & 1.2 & kW \\
\hline & & \multicolumn{2}{|c|}{ Max current } & 4.5 & $A$ \\
\hline \multirow{3}{*}{ Dynamometer } & \multirow{3}{*}{ Kistler 9257b } & \multicolumn{2}{|c|}{ Measuring range } & \pm 5 & $\mathrm{kN}$ \\
\hline & & \multirow{2}{*}{ Sensitivity } & $C D^{1}$ & 7.5 & $\mathrm{pC} / \mathrm{N}$ \\
\hline & & & $O D^{2}$ & 3.7 & $\mathrm{pC} / \mathrm{N}$ \\
\hline Charge amplifier & Kistler 5015A & \multicolumn{2}{|c|}{ Frequency range } & $0-200$ & $\mathrm{kHz}$ \\
\hline \multirow{2}{*}{$\begin{array}{c}\text { Digital } \\
\text { oscilloscope }\end{array}$} & \multirow{2}{*}{ PicoScope 4424} & \multicolumn{2}{|c|}{ Sample rate } & 80 & $\mathrm{MS} / \mathrm{s}$ \\
\hline & & \multicolumn{2}{|c|}{ Bandwidth } & 20 & $\mathrm{MHz}$ \\
\hline
\end{tabular}

$\mathrm{CD}^{1}$ : Cutting direction; $\mathrm{OD}^{2}$ : Orthogonal direction

\begin{tabular}{l|l|l}
\hline Equipment & Manufacturer & Model \\
\hline Stepper motor & IGUS & Nema 23 \\
\hline Motor driver & Nanotech & smcI36 \\
\hline Microtome & Thermo Fisher Scientific Inc. & HM355s \\
\hline Microscope for Slide & Zeiss & Axioplan 2 \\
\hline Microscope for Blade & Alicona & Infinite Focus \\
\hline Blade & & High profile \\
\hline
\end{tabular}

